\title{
Algunos elementos conceptuales y metodológicos para abordar los estudios multitemporales del ambiente
}

\author{
Some conceptual and methodological elements to \\ approach the environmental multitemporal studies
}

Ramón Alberto Serna Isaza*

\section{Resumen}

Aporta elementos pertinentes para abordar los estudios multitemporales de la transformación ambiental desde perspectivas holísticas, que impli can lecturas polisémicas de aspectos biofísicos, sociales, históricos y cul turales aportados por disciplinas diversas. Los "hechos" espaciales, conceptualizados como cargados de historicidad y connotaciones ordenadoras, son caracterizados por múltiples formas discursivas y condicionamientos ideológicos desde los paradigmas dominantes, y son implementados mediante prácticas homogeneizantes de adoctrinamiento, apropiación, aculturación, educación y desarrollo, que implican desco nocimiento de formas tradicionales de adaptación/adecuación socioambientales y generan nuevas espacialidades. Se propone el paisaje como categoría integradora que expresa las herencias de las relaciones dialécticas cultura naturaleza.

\footnotetext{
* Biólogo, Especialista en Sistemas de Información Geográfica, Magíster en Geografía. Correo e.: raserna@hotmail.com
} 
Palabras clave: Transformación ambiental multitemporal, Medioambiente, Relación cultura naturaleza, Paisaje, Posestructuralismo, Posmodernismo, Bioindicación.

\section{Abstract}

An approach toward the multitemporal environmental transformation's studies from a holistic perspective, based on the biophysical, social, his torical and cultural's polisemic interpretations, contributed by multiple disciplines.

The spatial "facts" are characterized by multiple forms of speeches and ideological constraints from the main paradigms, and implanted by in doctrinating, appropriation, plus some specific educational and develop ment models, and other homogenization practices that lead to cultural changes, which deny traditional social and environmental adaptable/ adequateness practices, that bring about new spatial possibilities. Land scape is proposed as an integrating category in which the inherited dia lectic relationships between nature and culture, are manifested.

Key words: Multitemporal environmental transformation, Environment, Culture nature relationship, Landscape, Post-estructuralism, Post $\sim$ modernism, Bioindication.

150 Ramón Alberto Serna Isaza 


\section{Introducción}

Al interpretar el pasado es insuficiente la pretensión positivista sobre la neutralidad de los "hechos" acaecidos en mundos que, aunque ya no son nuestros, han dejado improntas en nuestros días. Debido a la diversidad espaciotemporal abordada en estudios que abarcan procesos de ocupación desde tiempos prehispánicos, es usual el acercamiento a través de diversas fuentes, en las cuales el pasado es plasmado y mirado de acuerdo con los condicionamientos ideológicos de cada época (Ángel Maya, 1995: 9). Por ello, es importante hacer algunas anotaciones sobre las fuentes en las cuales se basan dicho tipo de investigaciones, así como sobre aspectos metodológicos y conceptuales relevantes para emprender dichos estudios.

El proceso histórico de vivenciación, transformación, recreación, conceptualización y apropiación de la naturaleza es abordado a través de diversas perspectivas que ayudan a su entendimiento. Se parte de una aproximación que nos permite la paleoecología, la antropología y la etnografía, a través de evidencias de la cultura material y cosmogonías de comunidades que habitaron en tiempos prehispánicos. Las perspectivas hispánicas coloniales son analizadas de acuerdo con las relaciones que nos dejaron los cronistas, se presentan ejemplos concretos para los muiscas, mientras que los primeros tiempos republicanos son plasmados a través de las descripciones de viajeros y los primeros analistas de la época. En los documentos que nos dejaron los cronistas, se llama la atención sobre el hecho de que los invasores europeos se arrogaron el derecho a apropiar, en un proceso que tiene rasgos muy peculiares en la forma como son vistas la naturaleza y los pueblos del Nuevo Mundo. Hacia finales del periodo colonial y durante el periodo republicano se enfatiza la manera como la ciencia y diversas formas propuestas de ordenar han estado orientadas hacia la expoliación, la apropiación de recursos, mano de obra y tierras, en una visión del campo que logrará plasmarse hacia mediados del siglo $\mathrm{xx}$.

En la segunda mitad del siglo xx cobra importancia el devenir sustentado en el desarrollismo y la planificación, que con valores como progreso y bienestar, especialmente material, han llevado al consumismo, fuertemente impulsado desde la cultura estadounidense, y han contribuido a la formación de mentalidades que han tenido gran influencia en la transformación de los ecosistemas y en la relación con la naturaleza. Esta perspectiva también está muy emparentada con la noción de progreso que ha permeado desde Europa y que de manera reciente se expresa en los planes de ordenamiento territorial. Ello ha hecho posible consolidar paisajes domesticados, jardines, campos de cultivo, ciudades... El progreso se identifica, por lo tanto, con una sempiterna lucha y dominio de la naturaleza que ha sido considerada un 
obstáculo al desarrollo, y con la implantación de la "civilización" sobre lo "salvaje", lo que se evidencia por el énfasis que los estudios ambientales ponen en los problemas, los impactos $\mathrm{y}$, en general, la relevancia dada a la naturaleza como factor de constreñimientos.

Muchas visiones, especialmente dentro de los enfoques economicistas, que plantean la búsqueda de la riqueza y el poder como una de las metas dilectas del existir humano, han tenido gran impacto en la relación con la naturaleza al considerarla inagotable $y$, de acuerdo con tradiciones judeo-cristianas, creerla destinada al servicio del hombre como centro de la creación. A partir de la década de los sesenta del siglo pasado, el ambientalismo ha venido imponiéndose como mentalidad alternativa, pero aún está lejano de alcanzar sus metas.

Como narrador en que se convierte quien escribe e intenta interpretar, también es actor político y agente moral $\mathrm{y}$, por lo tanto, comprometido a juzgar las consecuencias de las acciones humanas, tratando de entender las diversas opciones que enfrentan las vidas narradas y de las cuales se intenta, de alguna manera, aprehender su mundo. Nuestros valores estarán inexorablemente inmersos en este empeño de relatar lo significativo del pasado (Cronon, 2002: 57-58). El objetivo del presente documento, es, pues, aportar elementos para la interpretación de la gran diversidad espacio-temporal que involucra la tarea en cuestión.

\section{Derecho a conquistar, derecho a apropiar}

La visión española de las culturas americanas ha sido contradictoria. Al considerar a los indígenas como seres irracionales, los peninsulares tendrían derecho a sus tierras y a sus propiedades, pero al mismo tiempo implicaba que no estarían capacitados para recibir la fe cristiana, deslegitimando la conquista religiosa y espiritual del Nuevo Mundo (Nieto Olarte, 2000: 258). El derecho a la conquista parece basarse en el precepto aristotélico, planteado en la Política (Libro I, numeral 2, 1252a: 33, citado por Nieto Olarte, 2000: 258), según el cual "aquellos con una inteligencia superior son por naturaleza los amos y dirigentes de otros... los de juicio deficiente son por naturaleza sirvientes...".

Desde el inicio, la dominación había sido justificada bajo perspectivas legales y religiosas. Como cristianos, los conquistadores tenían el derecho y el deber de ocuparse de gentes que aún vivían en estado de "imbecilidad". La soberanía (imperium) y los derechos de propiedad (dominium) fueron directamente otorgados por el Papa al rey Fernando (Pagden, 1990, citado por Nieto Olarte, 2000: 258). El término "indias" se convirtió en palabra que denotaba cualquier ambiente en el cual vivían personas que desconocían formas adecuadas de vivir como seres humanos y que ignoraban la fe católica. La religión y la ciencia

152 Ramón Alberto Serna Isaza 
constituyeron símbolos de superioridad sobre los cuales se fundamentó la conquista (Nieto Olarte, 2000: 258259).

\section{Visión de la naturaleza en los invasores europeos}

El dominio cristiano en Europa, posterior a la caída del Imperio Romano, condujo a una repulsión de gran parte del conocimiento científico acumulado en el mundo griego y marcó la cosmología medieval. Fue preeminente la creencia teleológica judeo-cristiana sobre la creación y cuidados divinos del universo, como son relatados en el Génesis (Glacken, 1967: 153; Doughty, 1981, citado por Unwin, 1995: 94).

Dios crea el mundo a partir del caos reinante (Génesis 1, 1-24). En este proceso de perfeccionamiento crea al hombre a su imagen y semejanza para señorear sobre toda la tierra (Génesis 1, 26-27) y para cuyo goce y servicio están los frutos de la naturaleza, los cuales debe cultivar y cuidar (Génesis $2,15)$. Sin embargo, debido a la desobediencia de Adán y Eva a Dios, se rompe la relación idílica entre la naturaleza y el hombre, y desde entonces la humanidad ha tenido que luchar contra un entorno maldito (Génesis 3, 17). La caída del hombre es el origen del desorden de la naturaleza y la pérdida de sus poderes, perspectiva ampliamente difundida en el siglo XVII y alejada de la idea clásica de una senectud natural basada en la analogía orgánica (Glacken, 1967: 153). Esto tuvo gran impacto en el desarrollo posterior de las ideas geográficas sobre la relación entre el ser humano $\mathrm{y}$ el medio.

La religión judaica destruyó sistemáticamente los bosques sagrados de los pueblos sometidos de Palestina. Esta destrucción era un mandato de Jehová, el colérico y excluyente dios: «Mas así habéis de hacer con ellos [los enemigos]: sus altares destruiréis y quebraréis sus estatuas, y cortaréis sus bosques, y quemaréis sus esculturas en el fuego» (Deuteronomio, 7, 5-6). «Destruiréis enteramente todos los lugares donde las gentes que vosotros heredareis sirvieron a sus dioses, sobre los montes altos, y sobre los collados, y debajo de todo árbol espeso» [...] «sus bosques consumiréis con fuego...» (Deuteronomio, 12,2-3). «Talaréis sus bosques...» (Éxodo, $34,13)$.

El cristianismo y, su derivado, el catolicismo heredaron la abominación por los bosques y árboles sagrados de otros pueblos, herencia cultural y religiosa que pasó a América con los españoles (Patiño, 1977: 44).

En el Nuevo Reino de Granada los sacerdotes y misioneros españoles impusieron la tala de selvas y árboles sagrados de los muiscas para imponer la nueva religión. Relata el obispo Fernández de Piedrahita que «en el pueblo de Tenjo, en el sitio de El 
Palmar, está una carrera bien hecha que baja de lo alto del monte hasta el mismo lugar, en que había dos palmas bien elevadas y coposas ${ }^{1}$, de cuyas raíces nacía una hermosa fuente, que por haberse tenido noticias del respeto con que las veneraba la idolatría de algunos indios, fueron cortadas en el año de 1636 ó 37, por orden de don Francisco Cristóbal de Torres, arzobispo del Nuevo Reino» (Fernández de Piedrahita, 1942: I, 251). Parece que este fue el caso impuesto con gran intensidad en la Sabana de Bogotá:

Supieron los padres [jesuitas] que entre las casas del pueblo [Cajicá] estaban en pie algunos árboles junto a unos montecillos donde los indios antes que fuesen cristianos solían tener sus ídolos y ofrecerles sacrificios. Vínoles a los padres la noticia de esto porque inquirieron la causa del temor que tenían de sembrar en aquellos lugares y del miedo que mostraban en cortar algunos palos de aquellos árboles. Luego que supieron esta anticualla perniciosa la destruyeron, lo uno exorcizando aquellos lugares con los santos exorcismos de la Iglesia católica. Lo otro haciendo derribar aquellos árboles y levantando en su lugar los de las Cruces Santas que representaban al árbol en que Cristo murió crucificado. Con este hecho ahuyentaron a los demonios y animaron a los indios a que sin temor rompiesen aquellos pedazos de tierra y en ellos hiciesen labranzas de maíz, que es el trigo de que se sustentan (Mercado, 1957: I, 103, citado por Patiño, 1977: 45).

Es probable que aunque el daño ocasionado a la vegetación con estos procedimientos no tuviese mayor relevancia en regiones lluviosas, sí contribuiría a menoscabar el escaso patrimonio forestal de lugares como la sabana de Bogotá (Patiño, 1977: 46), en la que se podrían presentar enclaves con menores precipitaciones. Este sería un elemento importante en la aculturación de los pueblos sometidos.

Al comparar el comportamiento de grupos étnicos diferentes en el mismo territorio, se ha llegado a la conclusión de que mientras el aborigen o nativo tiende a ahorrar los recursos naturales, de los cuales deriva el sustento, la protección o el solaz, el alienígena o invasor los destruye con fines utilitarios inmediatos (Lopes, 1956: 254-256, citado por Patiño, 1977: 46), factores que están relacionados con la adaptación o adecuación cultural del medio.

\section{Los muiscas en las cróni- cas y los archivos}

En el proceso de construcción de una imagen de las sociedades y culturas aborígenes de América, los etnohisto-

\footnotetext{
1 Puede tratarse de la palma de cera, género Ceroxylon, que está restringida a los Andes ecuatoriales,
} especialmente a elevaciones superiores a los $2.000 \mathrm{~m}$. 
riadores han empleado información escrita en las crónicas de Indias, acudiendo más recientemente a los archivos civiles y criminales del periodo colonial. Generalmente los análisis de dichos documentos se han basado en conceptos desarrollados desde la antropología, que ha estado ligada con "modos occidentales de crear el mundo" (Strathern, 1988: 4, citado por Escobar, 1999: 50) y, por lo tanto, con formas de interpretarlos.

La sociedad muisca, que poblaba los altiplanos de Cundinamarca y Boyacá a la llegada de los invasores españoles en 1536 , es probablemente, de las sociedades prehispánicas de nuestro territorio, la que mejor documentada quedó durante el periodo colonial, merced a numerosas crónicas, relaciones y documentos que recogían y recreaban el pasado mítico de los muiscas, su cotidianidad colonial y las circunstancias de su conquista (Londoño, 1994: 107).

La crónica es definida como una "narración cronológica de carácter heroico: la saga de grandes sucesos y acciones de individuos destacados" (Tovar Zambrano, 1884, citado por Londoño, 1994: 108), además, la crónica constituyó una importante herramienta para reportar las riquezas americanas. La necesidad imperiosa de magnanimidad de los hechos, narrados en un Nuevo Mundo, fantástico de por sí, conduce a considerar el oficio del cronista tan importante como lo narrado:
Es gran don de Dios hacer los hombres cosas dignas de ser escritas, o escribir cosas dignas de ser leídas, y mucho más alcanzar lo uno y lo otro. Porque poco le importa a un valiente hacer cosas tan notables y dignas de eterna fama, si no hay quién se las escriba; pues si le falta esto, es cierto se entregan en manos del olvido que tiene por oficio sepultar cuanto a ellas le viene (Simón, 1981-1982, 1, 90).

Mas aunque con palabras apacibles, Razones sincerísimas y llanas, Aquí se contarán casos terribles, Recuentos y proezas soberanas: Muertes, riesgos, trabajos invencibles, Más que pueden llevar fuerzas humanas; Rabiosa sed y hambre perusina Más grave, más pesada, más contina [sic]. Veréis romper caminos no sabidos, Montañas bravas y nublosas cumbres. Veréis pocos e ya cuasi perdidos Sujetar increíbles muchedumbres De bárbaros crueles y atrevidos, Forzados a tomar otras costumbres. (Castellanos, 1955: 1, 60-61).

La etnohistoria hace uso de métodos tomados de la historia para, a través de conceptos de la antropología, enfrentarlos a sociedades y culturas del pasado (Londoño, 1994: 112). Surge entonces un problema mayor que debe ser tenido en cuenta al consultar estas fuentes y es el hecho de que quien se somete a análisis no son los cronistas mismos, sino indígenas que son descritos, entendidos $\mathrm{y}$, de alguna forma, vivenciados a través de los ojos de otra cultura. Simultáneamente aparecen contradicciones 
entre crónicas y documentos, ya que son géneros escritos con fines distintos.

Los documentos, como género no heroico, etnocéntrico, que maneja conceptos del siglo XvI, constituyen una fuente que no es primaria, pues su contenido es plasmado luego de ser filtrado por lo traducido o entendido por el traductor (a su lengua y cultura), o por lo que el oidor o el escribano decide consignar en las actas, o lo que el amanuense finalmente copia. Son por lo tanto productos de "creación colectiva", que se ocupan sobre todo de un presente colonial. Por otra parte, los cronistas pudieron registrar información aparentemente exótica bajo el rubro de "curiosidades de la tierra", especialmente cuando podían derivar alguna moralidad de ello, mientras que esto sólo ocurre en los documentos cuando incumben al buen gobierno colonial. Ambos tipos de escritos requerían ser creíbles por el español colonial y, por lo tanto, debían ser ajustados a la lógica europea. Bajo esta perspectiva, en los documentos se dio mayor credibilidad a los informantes ladinos, indios en mayor grado de aculturación, por su mejor entendimiento del español y la cultura europea. En oposición al término ladino, se empleaba el de chontal para indígenas poco embebidos en la cultura Occidental y se difundió para designar despectiva y etnocéntricamente a toda persona tenida por inculta y rústica (Londoño, 1994: 112, 116).

\section{Mirada fantástica de los cronistas}

Durante la conquista, España traslada a América su concepción del mundo y sus instituciones. Arrasa las formas de organización indígena existentes, para imponer las suyas. En consecuencia, el Imperio interpreta los imaginarios amerindios, los asimila y los incorpora mancillados a nuevas visiones y formas de organización. Este proceso fue consolidado de manera dramática por los conquistadores en su búsqueda de El Dorado.

Los cronistas del Nuevo Reino de Granada, al describir la naturaleza americana durante los siglos XVI, XVII y XVIII, siguieron la tradición clásica y medieval impuesta por los bestiarios y la historia natural, en los que predominó la idea del pensamiento trascendente, en el cual el conocimiento de la naturaleza está permanentemente remitido a un plano superior, el de la sabiduría divina, que constituye la clave para descifrar la condición del hombre. De esta manera, los cronistas nos dan una visión en la que existirá una relación muy próxima entre lo imaginario con lo real.

\subsection{Recreación literaria de la naturaleza del nuevo mundo}

Desde los descubridores del siglo xvI, en su proceso de asimilación de las realidades que van explorando, los 
cronistas expresan estar en otro mundo, el Alter mundus, lo que 'no soy yo', en la perspectiva de dos únicos mundos posibles, el nuestro y el de 'los otros', contrario del nuestro (Kappler, 1986, citado por Cavarcas Antequera, 1994: 41) y que influirá marcadamente en la vida cultural de occidente. Un Nuevo Mundo en el cual "el mundo se renovaba y se regeneraba, como devuelto a la gloria de los días de la creación" (Buarque de Holanda, 1987, citado por Cavarcas Antequera, 1994: 42).

En este proceso de encantamiento y extrañamiento emerge el lenguaje de lo imaginario, sustentado desde la fantasía popular y de lo establecido por las autoridades, que a fuerza de repetición pudo formar parte de los ensueños colectivos. El mundo americano descrito por los cronistas será su testimonio de realidad y de verdad. Conocer se asimilará en buena medida a reconocer lo que la cultura literaria y religiosa da como existente. Se presiente para esta naturaleza la proximidad del paraíso terrenal colmado de seres de singulares virtudes, a los cuales se realiza una aproximación, descripción y valoración que realza su apariencia y sus significados ocultos. En la exuberancia de la naturaleza americana se reconocen señales de la Providencia que aportan significados morales, los cuales hablan de "otra realidad", de orden superior (Cavarcas Antequera, 1994: 43-45).

\subsection{El lenguaje de lo maravilloso en los cronistas de Indias}

Con el antecedente del maravilloso medieval, ingresan los cronistas en la geografía americana. Para situarse a sí mismos y a sus probables lectores, comparan el mundo del que proceden con el que han encontrado, proceso en el que transforman el contenido cultural antiguo en un instrumento de conocimiento que permite dar sentido al mundo descubierto. La condición maravillosa de la naturaleza americana será acentuada al llevar los procedimientos comparativos hacia lo fantástico (Cavarcas Antequera, 1994: 47-49).

\subsection{Valoración de la diversidad en los cronistas de Indias}

Los cronistas se enfrentan a la contradicción que plantea el "desorden" de la naturaleza americana con respecto a la perfección y al orden conocido del universo creado por Dios. En esta "deformidad" reconocen una contribución a la belleza del universo a través de la diversidad que aporta. Con la observación y aceptación de la diferencia de la naturaleza americana, se revitalizan las visiones maravillosas y se amplían los repertorios de lo imaginario con nuevas maravillas, con las que se continúa el intento de adecuar la realidad a lo fabuloso y lo fabuloso a la realidad (Cavarcas Antequera, 1994: 49-50). 
A partir de los grandes descubrimientos del siglo $\mathrm{xv}$, que demostraron que estaban habitadas las partes de la Tierra que se consideraban despobladas, ocurrió una evolución de las ideas que simplificaban el mundo entre lo bello y lo feo, el bien y el mal, hacia la consideración de la relación existente entre esas categorías y la coherencia entre los espacios y los seres. Las expresiones de ese otro mundo serán testimonio de un mundo único y diverso, en el que cada ser es en el lugar que ocupa y existe con independencia de las categorías fijadas, ya que los antagonismos son su esencia. En América se confirmó la belleza, diversidad o semejanza del universo, hasta entonces solo conocido o imaginado por Dios (Cavarcas Antequera, 1994: 60).

\subsection{La fauna y la flora fantásticas en los cronistas de Indias}

Las tradiciones maravillosas medievales, especialmente las tradiciones 'animalísticas', fueron proyectadas al Nuevo Mundo, particularmente durante la conquista del Nuevo Reino de Granada, como se verá a través de unos pocos ejemplos ilustrativos.

Por ejemplo, una de las aves que concentró mayor interés de los europeos fue el colibrí o tominejo ${ }^{2}$ (Trochilidae), animal que constituyera el símbolo para representar la resurrección de
Cristo y la confianza en la inmortalidad, "epítome de la primavera y un casi invisible ramillete de todas sus flores" (Cobo, 1956, citado por Cavarcas Antequera, 1994: 120).

La zarigüeya (Didelphis marsupialis), marsupial muy abundante en el Nuevo Reino de Granada, fue más reconocido que celebrado. Debido a sus múltiples nombres, llegó a suponerse que no era un único animal. En tierra firme se le conoció como chucha o zaza, y como umasca en el Nuevo Reino de Granada (De León Pinelo, 1943, citado por Cavarcas Antequera, 1994: 132). Atrajo poderosamente la atención por su condición monstruosa: "cara de zorra, cola de mona, que adonde quiera que va lleva sus hijos en un vientre exterior a modo de bolsa grande" (Anglería, 1989, citado por Cavarcas Antequera, 1994: 132). Fray Pedro de Aguado lo llamó Homgod y lo asoció al tamaño de un zorro, comenta que las bolsas que tiene junto a las tetas se abren y se cierran como las pestañas de los ojos. Por su parte, Cieza de León describe que la chucha, al menor ruido, introduce a sus hijos en la bolsa, mientras León Pinelo argumentó que ante el peligro se traga a sus crías y luego las devuelve (Cabarcas Antequera, 1994: 132).

En los fisiólogos ${ }^{3}$ se explicaba que en el libro del Levítico se prohibía el

2 La palabra proviene de tomín, una medida colonial de peso muy pequeña (Fernández de Oviedo, 1995: 91).

3 Los bestiarios se derivan del Physiologus, tal vez el libro más popular de historia natural hasta el siglo XIII; su fama sólo es comparable a la de la Biblia (Guglielmi \& Ayerra, 1971, citado por Cabarcas Antequera, 1994: 12). 
consumo de comadreja o cualquier animal parecido (lo que incluiría a la zarigüeya), debido a que esta concibe a través de la boca y, una vez preñada, paría por las orejas. De la misma manera, algunos hombres comen el pan espiritual en la iglesia, pero apenas se alejan, arrojan la palabra divina fuera de sus oídos. A pesar de ello, y aunque el Nuevo Mundo era ideal para los anhelos de universalización del cristianismo, la exuberancia de su naturaleza aportaría la intuición de una vida menos rigurosa y más receptiva para el disfrute del mundo. En este ambiente, fray Bernardino de Sahagún, en el siglo XVI, asevera que se puede comer la carne de zarigüeya o de la comadreja, excepto su cola y sus huesos, porque estos hacen expulsar los intestinos a los perros y a los gatos que los consumen. A cambio de ello, la cola tiene la propiedad de sacar cuerpos extraños de huesos y músculos, sana la tos y ayuda a parir (Pinelo, 1943, citado por Cavarcas Antequera, 1994: 133). Es de destacar que esta costumbre de cortar la cola para poder consumir este marsupial se conserva en el campo hasta nuestros días.

La tradición medieval resalta que cada ser tiene su lugar en la jerarquía del universo y, como perteneciente al todo, expone y guarda sus virtudes y misterios. En concordancia con ello, se destaca el sustento que las plantas ofrecen al hombre, se exalta su posesión de alma y sus potencias que resaltan las grandezas de la obra de Dios. Son anunciadoras de tiempos venturosos en los que la vida se extiende sobre la muerte, expresando su condición sagrada y extraordinaria. Como habitantes de un mundo esférico, en el que no pueden estar separados los cuatro elementos que lo integran, cada elemento tiene dentro de sí las cualidades de los otros, con los cuales está unido e intercomunicado, ocasionando momentos de cruce que hacen posibles las transmutaciones (Cabarcas Antequera, 1994: 147-152).

En esta literaturización de la naturaleza americana son comunes las simbolizaciones dirigidas a intentar revalidar las escrituras, al tiempo que coexisten con fantasías que expresan visiones insospechadas que recrean incesantemente la realidad (Cabarcas Antequera, 1994: 120). La flora americana contenía así muchos de los secretos guardados por Dios.

Uno de los casos que se presenta con mayor recurrencia en los cronistas al describir flora con implicaciones religiosas se observa con las pasionarias, Passiflora spp., muchas de las cuales son nativas de los Andes ecuatoriales, pues, debido a la conformación de sus flores, son frecuentemente relacionadas con la pasión de Cristo.

También en el Nuevo Reino de Granada se encontraron plantas de "la monarquía del demonio", ya que causaron múltiples defunciones en los españoles:

Si ves que peleando lo más fuerte muere, razón no pide que te asombres; mas si morir de yerba fue la suerte es mal que de mil males tiene nombres. (Castellanos, 1955: II, 525). 
Puede citarse el caso de los borracheros (Brugmansia aurea y $B$. sanguinea), ampliamente difundidos en las montañas andinas, los cuales presentan un doble carácter: son usados como tóxicos y medicinales, pero también presentan un importante componente ornamental. El borrachero era usado en la muerte de los soberanos muiscas para que las mujeres y esclavos que eran enterrados con ellos soportaran dicho tránsito:

$Y$ para que no sientan las mujeres ni los esclavos miseros su muerte, antes de ver la cueva monstruosa les dan los xeques ciertos bebedizos del ebrio tabaco, y otras hojas del árbol que llamamos borrachera en su común bebida disfrazados, con que de las acciones del sentido nada les queda para ver su daño. (Castellanos, 1955: IV, 168-169).

Otro ejemplo de uso tóxico-medicinal se puede consignar cuando los españoles llegaron a la Sabana de Bogotá por el costado de Chocontá, hacia 1536 , en donde fueron intoxicados con estas plantas: «La causa de la dolencia pasada se originó de que las indias que iban violentadas en servicio de los españoles, echaron en la comida cierta yerba llamada «tetec», y vulgarmente «borrachera», que causa los efectos conformes al nombre que tiene, sin que pase a más daño que al referido; e hiciéronlo con el fin de poderse huir al tiempo que sus dueños estuviesen fuera de sí, como en efecto lo consiguieron muchas» (Fernández de Piedrahita, 1942: II, 27).

Al avanzar el proceso de aculturación, el borrachero había perdido gran parte de su influencia y uso como narcótico, de tal forma que hacia 1701 los floripondios solo son mencionados como plantas de adorno en el Nuevo Reino (Zamora, 1930, citado por Patiño, 1967: 274) ${ }^{4}$. Sin embargo, con el proceso de difusión de plantas se hace nuevamente común el uso tóxico, tanto de Brugmansia spp. como de Datura stramonium L., otra Solanaceae próxima a esta, por parte de los ladrones para narcotizar a sus víctimas.

Vale la pena revisar de manera concisa la percepción sobre las provisiones de mayor difusión que encontraron los españoles al llegar al altiplano cundiboyacense.

La expedición que viajaba con Gonzalo Jiménez de Quesada conoció, en su entrada al Nuevo Reino (1537), las papas en los bordes de la confederación y las reconoce como principal mantenimiento de los muiscas; estas son descritas como "unas a manera de turmas de tierra que llaman «Yomas»"

\footnotetext{
Llama la atención que en los cronistas es clara esta mutación de nombres que acompañan al cambio de uso. Así, inicialmente esta planta es llamada borrachero (a), flor de baile, Huanto, huántuc (en quechua, probablemente derivado de wántukk: que lleva, carga o transporta valiéndose de un medio; Lira, 1945, citado por Patiño, 1967: 273), por el estado de intoxicación en que queda quien lo ingiere. En cronistas tardíos es llamada floripondio por su uso ornamental.
} 
(Jiménez de la Espada, 1889, citado por Patiño, 1967: 206) o ionas e iomas (Cuervo, 1892: II, Friede, 1960, citados por Patiño, 1967: 206). Viajando por la margen izquierda del río Suárez, son descritas de la siguiente forma:

(...)entraron por las grandes poblaciones de Sorocotá, ya todas desiertas, con el mismo temor de sus vecinos, aunque las casas todas proveídas de su maíz, fríjoles y de turmas, redondillas raíces que se siembran $y$ producen un tallo con sus ramas, $y$ hojas y unas flores, aunque raras, de purpúreo color amortiguado; y a las raíces desta dicha hierba, que será de tres palmos de altura están asidas ellas bajo tierra, del tamaño de un huevo más y menos, unas redondas y otras perlongadas: son blancas y moradas y amarillas, harinosas raíces de buen gusto, regalo de los indios bien acepto, $y$ aun de los españoles golosina. (Castellanos, 1955, IV, 186-187).

A pesar de que el maíz -particularmente el blanco- se encuentra asociado a ofrendas religiosas y a fines ceremoniales, mágicos o ritualísticos en los pueblos americanos (Patiño, 1964: 107) fue señalado por múltiples cronistas durante la conquista española básicamente por su papel en la alimentación, a tal punto que fue reconocido por el cronista Zamora como "el trigo de los naturales de América” (Gómez Bernal, 2002: 73).

\subsection{Piedras y minerales quiméricos}

El sueño de alcanzar riquezas en América incluyó múltiples ideales que operan simultáneamente. Algunos fueron buscados por su pragmatismo y su importancia material, pero también actuaron las imágenes del mundo medieval en la convicción que en América existían piedras y metales con virtudes singulares, que procuraban una continuidad entre los hechos puramente físicos y las aspiraciones espirituales, al tiempo que con su belleza acercan al hombre a la vida de los cuerpos celestes (Cabarcas Antequera, 1994: 166-172). Estas piedras preciosas son engendradas y poseedoras de virtudes múltiples: "son hijas de la luz y de la tierra; a unas engendra el sol a rayos y a otras la aurora a sentimientos, y así, la más preciosa pesa menos" (Oviedo, 1930: 23).

\section{Aculturar para dominar: transculturación ${ }^{5}$}

Después de la conquista, la multiplicidad étnica y cultural de las diversas culturas indígenas fue reducida a un estrato común de "indios", homogeneización que generó pérdida de las diferentes tradiciones americanas y de identidad (Morse, 1987, citado por Nieto Olarte, 2000: 259).

\footnotetext{
La transculturación involucra las fases del proceso de transición de una(s) cultura(s) a otra(s), esto es, la pérdida de una cultura antecedente o deculturación y la creación de fenómenos culturales nuevos o neoculturación (Ortiz, 1973, citado por Ceballos Gómez, 1995: 15). La aculturación implica la adaptación a un patrón cultural diferente, por lo que va unida a la deculturación y a la transculturación, procesos dinámicos propios de las culturas (Ceballos Gómez, 1995: 15).
} 
Los conquistadores europeos fueron muy permeados por las culturas de sus colonizados y esclavizados. La sociedad colonial estaba jerarquizada institucionalmente, reflejo de la jerarquización política, con una correspondiente identificación en el orden social, que a su vez reforzaba el sistema de poder (Colmenares, s.f., citado por Ceballos Gómez, 1995: 17). El control de la sociedad era asunto de todos, penalizándose los comportamientos socialmente prohibidos. En esta categoría recaían las manifestaciones culturales, los conocimientos empíricos (sobre yerbas medicinales, enfermedades, venenos, etc.) y los comportamientos lúdicos de las culturas dominadas (Ceballos Gómez, 1995: 17) .

La marcada estratificación social generó conflictos y lucha de las culturas blanca, negra, indígena y la mestiza resultante, que por su naturaleza no estaba sujeta a una explícita relación de subordinación (Álvarez, 1983, citado por Ceballos Gómez, 1995: 18). Los criollos hicieron toda clase de esfuerzos para probar su origen español y así adquirir los privilegios de la sociedad europea. En este sentido, trataron de deshacerse de cualquier rastro de origen no europeo, para lo cual evitaron ocupaciones manuales "bajas", sin reconocimiento social e impropias de las élites criollas. Sobre todo, buscaron obtener un título universitario en medicina, leyes o teología (Nieto Olarte, 2000: 259).

Los indígenas conformaron un grupo silente, muchas veces inerme, cuyo estatuto real era inferior al de los esclavos, ya que a diferencia de estos, los indios se cuidaban por sí mismos, se consideraba que había "suficientes" (por lo menos hasta el siglo XVII), eran gratuitos, producían rendimientos y si morían, nadie perdía "nada". Su hostilidad y los conocimientos del medio natural que poseían muchos de ellos, al igual que el manejo de prácticas médicas, adivinatorias, hechiceriles $\mathrm{y}$ chamánicas, se tradujo en un profundo temor del "otro" y sus saberes (Ceballos Gómez, 1995: 19), por lo que la mencionada autora plantea que para hacer una historia de los españoles en América debe realizarse también una historia del miedo al otro.

Aculturar y homogeneizar constituyeron una necesidad política que permitiría un control incipiente en un continente indómito, colmado de pueblos nativos con culturas y lenguas diferentes, además de diversas culturas africanas aportadas por los esclavos, aunado a la diversidad de pueblos españoles. La estrategia dominante para la dominación ideológica giró en torno a la religión, proceso que fue exacerbado por la Inquisición, tan en boga en Europa en el momento de la

6 Esta misma autora nos recuerda que los derechos individuales nacieron con la Revolución francesa, y con ella, el privilegio de la intimidad.

162 Ramón Alberto Serna Isaza 
conquista de América (Ceballos Gómez, 1995: 20-21). Sin embargo, a pesar de siglos de esfuerzos del cristianismo para suprimir sistemáticamente las tradiciones culturales aborígenes, no fue posible erradicar las costumbres y creencias de las culturas de los Andes. De esta forma, cuando las expediciones ilustradas llegaron a América, encontraron tradiciones con elementos indígenas, católicos y africanos (Nieto Olarte, 2000: 141).

El control se inicia con la imposición del castellano, con lo que se logra un código común, al tiempo que se disgregan y atomizan las estructuras sociales de los dominados. Los dominicos, evangelizadores de los muiscas, obligaron a los habitantes del altiplano cundiboyacense a aprender español, logrando una gran fragmentación y la desaparición de la lengua chibcha. Con ello, al ingresar a otro "modo de ser lingüístico", también se ingresa a otro "modo de ser cultural", lo que implica otras formas de pensar el mundo y de relacionarse con él, proceso de desarraigo religioso, social, político y cultural (Ceballos Gómez, 1995: 23).

En 1565 fue fundado el primer colegio bilingüe (lengua chibcha y castellana), para los hijos de los caciques e indios principales de Santafé. Como en este tipo de educación solo tomó parte un pequeño sector, la interiorización de la religión y el aprendizaje del idioma fueron más lentos de lo esperado. Los indígenas se mostraban pasivos en los ritos y ceremonias católicas ante los ojos de los españoles. Para el indio, la participación se daba a través de las borracheras que reproducían en los días de ir a misa o de guardar y aunque se bautizaban y cumplían con los preceptos formales, no participaban abiertamente en las ceremonias religiosas (Llano Restrepo \& Campuzano Cifuentes, 1994: 49).

Hacia 1560, gran parte de los indígenas "urbanos" se encontraban en esta situación ante la Iglesia. No entraban a misa, ya que poco conocían su significado y preferían emborracharse con chicha, bebida cercana a sus festejos y rituales. Incluso, un edicto de 1687, dictado por el arzobispo Urbina, conducente a evitar las borracheras de los indígenas so pena de excomunión y la consecuente expulsión del catolicismo, tuvo que ser anulado, ya que resultaba muy drástica la medida, cuando aún no se había consolidado el proceso de conversión. Ya hacia el siglo XVIII, principalmente, los indígenas participaban más activamente en las ceremonias religiosas, asistían a las procesiones, daban limosnas a las cofradías y tenían un Santo Patrón. Sin embargo, esta participación estaba fuertemente influenciada por su bagaje cultural, ya que en las prácticas rituales muiscas se hacían procesiones y en ellas se celebraban fiestas especiales ofrecidas a las cosechas, a los ciclos naturales o a la investidura de un alto funcionario, celebraciones en las que la borrachera constituía parte fundamental. Esta incontrolable 
situación fue repelida en todo el Nuevo Reino de Granada a través de Real Cédula de 1748, que ordenó "se cerrasen en los días de fiesta las pulperías en que se vende la bebida llamada vulgarmente chicha por los gravísimos daños que ocasiona, así en lo espiritual como en lo temporal..." (Llano Restrepo \& Campuzano Cifuentes, 1994: 49-50).

Con las medidas coercitivas emitidas durante la colonia, aparecen espacios especializados para beber chicha, cuyo consumo ya no se restringe a momentos colectivos importantes, sino que se relaciona con decisiones individuales. Se conduce, de esta manera, a la pérdida de las pautas de consumo y del significado ritual del acto (Llano Restrepo \& Campuzano Cifuentes, 1994: 150). En este, como en tantos otros procesos, se trasluce una posición ideológica peyorativa frente a la herencia indígena.

\subsection{Ordenar para controlar}

La forma como se estructuró en los Andes centrales el ordenamiento espacial y jurisdiccional, a fines del siglo XVI y principios del XVII, consolidó espacios a partir de los cuales se logró el control de la población indígena, al igual que el de mestizos o vecinos que se incorporaron al territorio jurisdiccional. Los pueblos de indios constituyeron canales efectivos para difundir mensajes del Estado colonial, a través de la regulación del tiempo y el espacio para el desarrollo de activida- des de socialización. En este sentido, la iglesia y la plaza constituyeron espacios en los que se materializaba el poder, y a través de mensajes implícitos se lograba incorporar el sistema jerárquico en el que se fundamentaba la sociedad colonial (Herrera Ángel, 2002: 32).

Estas medidas también permitieron a las autoridades ejercer una vigilancia continua sobre la población radicada en los pueblos y sus alrededores. A pesar de que la mayoría de blancos, mestizos y esclavos no vivían dentro de los pueblos de indios, estaban permanentemente vinculados a estos, gracias a la periodicidad de los mercados y los oficios religiosos. La articulación de pautas culturales indígenas, europeas y africanas se realizaría bajo la supervisión de curas y administradores coloniales, que tuvieron la capacidad de inculcar valores y prácticas de comportamiento que el Estado estaba interesado en fijar en los habitantes de las colonias (Herrera Ángel, 2002: 34).

\subsection{Historia natural y apropiación del nuevo mundo}

Los viajes de exploración constituyeron el centro de intereses políticos, públicos y comerciales de las élites europeas durante el siglo xviII. De acuerdo con los preceptos de la Ilustración francesa, el gobierno español centró su política en la adquisición y aplicación de conocimientos científicos para aumentar su poder económico y político, a través de una explotación

164 Ramón Alberto Serna Isaza 
eficiente de la riqueza natural de sus colonias (Nieto Olarte, 2000: 9-10).

Claro ejemplo lo constituye la aprobación de la Expedición Botánica, promovida por la Corona española en el Nuevo Reino de Granada, con el fin de buscar nuevos recursos sobre los cuales reorganizar la economía, hasta el momento basada en gran medida en la explotación de las minas de oro y plata, y con estos nuevos recursos continuar sosteniendo guerras. Como director fue nombrado José Celestino Mutis, a través de Cédula Real, firmada por el Rey el 1 de noviembre de 1783:

... no sólo para promover los progresos de las ciencias físicas, sino también para [...] aumentar el comercio, y que se formen herbarios $\mathrm{y}$ colecciones de productos naturales, describiendo y delineando las plantas que se encuentren en aquéllas mis fértiles provincias para enriquecer mi gabinete de historia natural y jardín botánico de la corte, y remitiendo a España semillas y raíces vivas de las plantas y árboles más útiles, señaladamente de las que se empleen o merezcan emplearse en la medicina y en la construcción naval, para que se connaturalicen en los varios climas conducentes de estas penínsulas, sin omitir las observaciones geográficas y astronómicas que se puedan hacer de paso en adelantamiento de estas ciencias... (Vezga, 1971: 128-129).

El conocimiento de la historia natural se constituyó en la clave para el mejoramiento del comercio y de las manu- facturas. La clasificación se convirtió en proyecto de primordial importancia, basado en los códigos de la taxonomía linneana.

Esta visión comercial y utilitaria está sustentada por una concepción religiosa de la naturaleza. Los viajeros naturalistas formaron parte de una cultura convencida de que todo el universo estaba regido por leyes preestablecidas, dentro del cual, y de acuerdo con el sistema desarrollado por Linneo, el género y la especie constituyen las categorías más importantes y son las unidades esenciales de la obra de Dios. Para Linneo, la tierra no es más que un "gabinete de historia natural que contiene las obras maestras del omnisapiente creador" (Linneo, 1754, citado por Nieto Olarte, 2000: 51) y el hombre es la criatura para quien todo lo demás habría sido creado (Nieto Olarte, 2000: 51).

Como disciplina, la historia natural se construye sobre redes que requieren que las muestras del mundo natural sean movilizadas desde lugares remotos (las colonias) hacia el centro (el imperio). Para ello es necesario desarrollar técnicas de preservación o representación de los objetos. Adquiere gran importancia el papel de los botánicos y taxónomos como conocedores del sistema que intenta universalizar códigos que permitan acumular y transferir información a dichos centros (Madrid, Londres o París), al igual que las técnicas de los herbolarios y los dibujantes. 
La representación gráfica permite simplificar la complejidad de la naturaleza; los especímenes se preparaban para ser presentados en Europa como nuevos descubrimientos. El conocimiento sobre los ecosistemas ecuatoriales era producido y aprobado en instituciones europeas como laboratorios, jardines botánicos, imprentas y museos; la complejidad y diversidad de especies vegetales era reducida finalmente a principios cuantificables (Nieto Olarte, 2000: 69-70, 174). El botánico adquiría una posición privilegiada en la centralidad, gracias a su visión estandarizada de la naturaleza, esto es, conforme con un sistema normativo en el lenguaje, los códigos y las reglas, que eran respetadas en la red en la cual se movilizaba dicha información (proceso que en taxonomía está relacionado con la diagnosis del espécimen).

El interés radica en consolidar un sistema único que permita acumular y catalogar todos los objetos de la naturaleza y la apropiación de los objetos naturales de cualquier parte del mundo (Nieto Olarte, 2000: 122).

Los nombres locales de plantas y animales fueron reemplazados por otros ajenos a su origen, ahora relacionados en múltiples ocasiones con agentes del imperio. Esta apropiación estuvo lejana a los preceptos anticolonialistas promovidos en el Siglo de las Luces por Rousseau y, atenuadamente, por Voltaire.

A pesar de la pretendida originalidad de los "descubrimientos" sobre plan- tas útiles que se arrogan los botánicos de la época, a través de la supuesta observación directa de la naturaleza, es mucho más probable que haya sido el resultado de apropiación del conocimiento local de las comunidades (y cuya legitimación como conocimiento válido era posterior a su traducción) $\mathrm{o}$ de asociación de especies que ya tenían reconocimiento en Europa, proceso de bioprospección que aún sigue siendo ampliamente utilizado por compañías farmacéuticas multinacionales o por investigadores tanto nacionales como extranjeros. "Descubrir" y describir "nuevas especies" permite apropiar, traducir y desplazar el conocimiento y la naturaleza americanos al comercio europeo (y de manera más reciente a otras centralidades).

En el proceso de traducción pueden ser identificadas tres etapas (Nieto Olarte, 2000: 174): en una primera, las tradiciones y leyendas populares sobre descubrimientos son promovidas por los exploradores, con lo que se genera interés y credibilidad en las conclusiones propias. En la siguiente, los botánicos identifican taxonómicamente la planta. Por último, estas son reducidas y analizadas en sus componentes químicos. Esto dio como resultado que el conocimiento médico, las substancias aisladas y la comercialización fueran de propiedad exclusiva de una comunidad cuyos intereses y poder permanecería centrado en Europa. Así, la exploración botánica formó parte del proyecto europeo de reordenar el mundo. 
El interés durante el siglo XVIII en las plantas medicinales responde a una política de substitución de importaciones, encaminada a reemplazar productos medicinales y especias que eran llevados a Europa desde Oriente, a través de un mercado dominado por países europeos como Inglaterra y Holanda (Nieto Olarte, 2000: 139).

Desde 1570, con el nombramiento de los protomédicos de las Indias por Felipe II, a través de una Cédula Real, el gobierno español había promovido la incorporación de productos medicinales americanos: “Todas las hierbas, árboles, plantas o semillas con cualquier valor medicinal que se pueda encontrar en aquellos lugares serán enviados a este Reino..." (Causape, 1973, citado por Nieto Olarte, 2000: 139). La recopilación sistemática del conocimiento médico de los nativos comenzó solo en 1574, por orden expresa dada en una Cédula Real. Los resultados fueron publicados en 1597 con el título de Instrucción y memorias de la descripción de las Indias que su Majestad mandó hacer para el buen gobierno y ennoblecimiento dellas, documento que recoge, traduce y reinterpreta conocimientos de caciques, hierbateros y curanderos, a la luz de las ideas de Hipócrates y Galeno (Bynum \& Nutton, 1981, citado por Nieto Olarte, 2000: 139). Se prestaba muy poca atención a las creencias de los indígenas o sus prácticas religiosas, que por principio eran consideradas supersticiosas e inútiles (Nieto Olarte, 2000: 139).

\subsection{La tradición científica colombiana}

A pesar del planteamiento, repetido en la historiografía, de que Mutis fue el maestro a quienes los naturalistas americanos deben tanto su educación como sus ideales revolucionarios, es claro que este no contempló nunca la posibilidad de ser reemplazado, ni de tener un sucesor en América: "Luego que yo falleciere, deberá quedar extinguido el empleo de Director de la Real Expedición Botánica de este Reino" (Mutis, 1986, citado por Nieto Olarte, 2000: 240).

Así como los sacerdotes cristianizaban a los nativos, salvaban sus almas y civilizaban a los salvajes, el médico salvaba sus cuerpos. Se imponía así un patrón de dominación y autoridad de las metas y métodos propios de Europa. Dentro de este proceso de educación de los nativos, como nueva forma sistemática de control e intervención cultural, puede verse a Mutis como claro representante (Nieto Olarte, 2000: 247).

Hasta ese momento, cuando las reformas propuestas por Mutis comenzaron a tomar forma en la Universidad, la enseñanza de la medicina europea había tenido poco éxito y escaso efecto en la cultura local. Solo dos médicos recibieron sus títulos en Santafé de Bogotá entre 1603 y 1802 (Quevedo, 1992, citado por Nieto Olarte, 2000: 250). El interés del Estado para promover y mejorar la profesión médica, 
tanto en las colonias como en España, llegaría en el siglo XvIII con las reformas ilustradas, que buscaban reducir el poder administrativo del clero a través del fortalecimiento de la administración estatal. Para poder ingresar a la universidad y ser examinado como doctor era necesario pasar la "prueba de sangre", lo que significaba estar libre de ancestros indígenas, mulatos, negros o esclavos (Nieto Olarte, 2000: 250).

El nuevo proyecto de "conciencia planetaria", representado por la ciencia colonial de los siglos XVIII y XIX, con foco en la exploración de los continentes y la imposición de unos valores y una cultura en particular (Pratt, 1992, citado por Nieto Olarte, 2000: 254), implicó incorporar la naturaleza en un patrón de orden y unidad cristianos, centrado en una visión teleológica y funcional de la naturaleza, que se considera creada para el hombre, en particular el europeo. La historia natural comienza a ser practicada no solo por viajeros, sino también por habitantes nativos, que conforman una élite americana interesada en adoptar las ambiciones y métodos de la ciencia europea (Nieto Olarte, 2000: 254-256).

Mutis y otros científicos europeos, que vivieron gran parte de su vida o murieron en América, no solo entrenaron en medicina o historia natural a nativos, sino que fundaron instituciones que se convirtieron en símbolos de poder local y de diseminación de una ideología de apropiación, como jardi- nes botánicos, museos, observatorios astronómicos y cátedras universitarias. Este grupo conformaría una élite de americanos con sangre europea, cultura con la cual parecían sentir una fuerte identificación, sentimiento que era alimentado por el propósito de la ciencia ilustrada de explotar y conocer la riqueza natural del nuevo continente, aunque sin el debido reconocimiento de las cortes europeas (Nieto Olarte, 2000: 256).

Los compromisos de la Ilustración europea comenzaban a ser incorporados para las necesidades de no-europeos. El "patriotismo" de esta élite ilustrada criolla no puede ser separado de la clase social y los intereses de una minoría. Por ejemplo, en opinión de Francisco José de Caldas, los nativos carecen del conocimiento para mantener el equilibrio natural, por lo que considera que la protección del patrimonio natural debe recaer en manos de caballeros terratenientes (Caldas, 1966, citado por Nieto Olarte, 2000: 265-266).

Durante la revolución de la independencia, esta élite luchaba por sus derechos como terratenientes, comerciantes, mineros y propietarios de esclavos, derechos similares de posesión y control de los europeos. Se pretendía así que los ideales de libertad e igualdad (basados en los ideales de la Revolución francesa), preconizados por los líderes de la independencia, se limitaran a aquellos que fueran educados y adinerados. Bolívar plantearía 
que los líderes de la revolución son los blancos, los ricos y los títulos de Castilla (Bolívar, s.f., citado por Nieto Olarte, 2000: 266-267). Todos los miembros de la Real Expedición Botánica fueron aristócratas cuyos intereses políticos y científicos los involucraron en el proceso de reposesión de América, que, según lo expresó Jorge Tadeo Lozano, conformaría "un vasto imperio que en pocos siglos será émulo de los más poderosos de Europa" (Hernández de Alba, 1991, citado por Nieto Olarte, 2000: 268). Luego de la independencia, algunos de ellos alcanzaron notable poder, como sucedió con Francisco Antonio Zea, quien fue nombrado vicepresidente de la Gran Colombia.

Las élites que ayudaron a crear nuevas naciones americanas aportaron sobre todo en la consolidación de las tradiciones europeas en América. Contribuyeron a diseminar ideologías e instrumentos de apropiación que reforzaron mecanismos de control de las colonias por un grupo de criollos privilegiados. Esto cooperó en la reducción del poder de los nativos para controlar sus propias vidas (Nieto Olarte, 2000: 271-272), como es brillantemente ejemplificado por algunas novelas del siglo XIX (ver p. ej. Samper Ortega, 1937).
Para estas élites, hacer ciencia era considerado hacer patria, y construir una sociedad científica organizada podría asemejarse a construir nación. El conocimiento sólo se justificaba en la medida en que era puesto al servicio del país, aunque se estimulaba la recompensa en fama, fortuna y gloria que rendiría el estudio de la naturaleza. El discurso sobre el saber denota la creencia en torno a la inamovilidad de los resultados de la ciencia, acompañados del símil de la luz y la razón, mientras las imágenes bíblicas preconizan paciencia para recoger frutos, llaman a la constancia, a los propósitos de largo plazo (Obregón, 19881989: 141-143, 159).

Sin embargo, en los albores del siglo XIX surgen también nuevos sentidos en la concepción de naturaleza vegetal. Es posible pasar de la búsqueda de la armonía universal en concordancia con la voluntad de Dios, a comprender dimensiones específicas de la naturaleza que la fragmentan en paisajes, manifestaciones de una naturaleza autónoma con relación a Dios, regulada según sus propias leyes y ritmos (Castrillón, 1997: 61) ${ }^{7}$. Desaparece la fisonomía propia de cada familia vegetal y predomina la del conjunto formador del paisaje:

En este aspecto debe destacarse la influencia científica que tuvo sobre las élites ilustradas la presencia de Alexander von Humboldt, quien llegó en 1801. En su Geografía de las plantas, asienta las bases de la ciencia del paisaje y específicamente de la fitogeografía, al intentar comprender la relación de los grupos vegetales con el medio. En estos análisis integró informaciones climáticas, topográficas, astronómicas, geológicas y taxonómicas con una consideración estética. 
Los medios apropiados para difundir el estudio de la naturaleza consisten [...] en tres formas particulares bajo las cuales se manifiestan el pensamiento y la imaginación creativa del hombre: $1^{\circ}$ la descripción animada de las escenas y de las producciones de la naturaleza; $2^{\circ}$ la pintura del paisaje, desde el momento en que se comienza a percibir la fisionomía de los vegetales, su abundancia salvaje y el carácter individual del suelo que los produce; $3^{\circ}$ el cultivo más difundido de plantas tropicales y las colecciones de especies exóticas en los jardines y en los invernaderos (Humboldt, Cosmos, 1848: t.2, 2, citado por Castrillón, 1997: 72-73).

Emerge el paisaje como herramienta epistémica para conocer la naturaleza vegetal, diferente al discurso científico. Viajar y explorar se convierten en condiciones para construir el saber naturalista del siglo XIX. El naturalistaviajero recorre la superficie de la tierra en su intento por hacer visible su composición y organización, proceso en el que conjuga la precisión de los discursos científicos, la sensibilidad de la palabra y del pincel, para construir los cuadros de la naturaleza (Castrillón, 1997: 81).

A lo largo del siglo XIX seguirían los esfuerzos por continuar con las tareas de la expedición. En 1811, la constitución de Cundinamarca establecía una sociedad patriótica que sentaba las bases para una política de apropiación local:

Deberá establecerse cuanto antes en la capital una Sociedad Patriótica, así para promover y fomentar estos establecimientos en ella y en toda la Provincia, como para hacer otro tanto en razón de los ramos de ciencias, agricultura, industria, oficios, fábricas, artes, comercio, etc. [...] Entre los demás establecimientos, se tendrá presente el de la Expedición Botánica, para extenderlo, además de los trabajos en que hasta ahora se hubiese empleado, a la enseñanza de las ciencias naturales, bajo la inspección de la Sociedad Patriótica (Historia documental, s.f., citado por Nieto Olarte, 2000: 270).

Durante las primeras décadas de la República se hicieron grandes esfuerzos por importar ciencia. Así, en 1823, gracias a las gestiones de Zea, se aprobó la contratación de cinco naturalistas franceses para la fundación de un Museo Histórico Natural y una Escuela de Minería en Santafé (Safford, 1985, citado por Nieto Olarte, 2000: 270). En 1832 se reorganiza la Academia Nacional de Ciencias, sin ningún éxito. En 1849 se establece la Comisión Corográfica de los Estados Unidos de Colombia, para reafirmar la nacionalidad a través de la investigación sistemática, la definición de zonas baldías para ser incorporadas en la producción económica, elaborar la cartografía del territorio nacional y redefinir fronteras (Díaz-Piedrahita, 1991: 59-60; Peña Roa, 2001: 21).

En 1867 se funda la Universidad Nacional de los Estados Unidos de Colombia, manejada por una élite ilustrada que pretendía unificar el país a

170 Ramón Alberto Serna Isaza 
través de la "instrucción pública", la ciencia y los estudios aplicados a la agricultura, la minería y la industria. Con estas medidas se pretendía ejercer control sobre los artesanos, grupo de gran presión social que se opuso en repetidas ocasiones, durante el siglo XIX, a la implantación del modelo económico del librecambio. A pesar de estos planteamientos, la ciencia no tuvo la fuerza suficiente para reconciliar la nación, profundamente dividida por una gran fragmentación regional (Obregón, 1988-1989: 153-158).

Durante la segunda mitad del siglo xIX, la ciencia era un lujo más que ocupaba parte del tiempo de la élite, una afición que no permitió la institucionalización de la ciencia, ni el científico cumplió un papel social transformador. La ciencia fue usada como argumento político, gracias al prestigio que a ella otorgaban los modelos emulados, al tiempo que legitimaba su propio poder y fue empleada como argumento para lograr un pretendido progreso del país y como factor de contribución a la unidad nacional (Obregón, 1988-1989: 160-161).

La difusión regional de las ideas es, por lo tanto, un proceso altamente influenciado y dirigido por las élites ilustradas. A manera de ejemplo, para zonas andinas colombianas tuvieron gran preeminencia los planteamientos plasmados en El Agricultor, revista de cuyo cuerpo de redacción hizo parte don Carlos Michelsen, con los doctores Camacho Roldán y Carrasquilla, en donde constan numerosas observaciones sobre régimen de lluvias, cosechas, abonos, enfermedades de los ganados y otros temas. El Dr. Michelsen fue el primer jefe de sección de agricultura del Ministerio de Fomento, y a su iniciativa se debe la traída del profesor Vericel, que tuvo tanto influjo en la ganadería en Colombia y en particular en la sabana de Bogotá. El Dr. Michelsen fue poseedor de las haciendas Las Monjas y Las Monjitas, en inmediaciones del río Bojacá, mientras que el Dr. Camacho Roldán lo fue sobre tierras en inmediaciones de La Ramada (actualmente conectada con el Distrito de Riego de Bojacá-La Herrera).

La ciencia local ha continuado marcada por el esfuerzo de ser reconocida internacionalmente, lo que no ha permitido la consolidación de una sociedad científica nacional que tenga un impacto verdadero sobre las necesidades de la sociedad colombiana (Nieto Olarte, 2000: 273). Aún predominan las visiones disciplinares, como las promovidas desde la fundación de la Facultad de Ciencias de la Universidad Nacional de Colombia, en 1965, y las diversas facultades de ingeniería. De manera reciente, académicos nacionales intentan promover la búsqueda autopoiética con recursos intelectuales y prácticas propias, que permitan desarrollar marcos científicos, técnicos y un conocimiento que conduzca a una mayor equidad, autoestima y valoración de la diversidad (ver p. ej. Fals Borda y Mora-Osejo, 2001: 1-6). 


\subsection{El economicismo y el desarrollo como nuevas formas de apropiación de la naturaleza}

La economía, como dominio independiente, aparentemente separada de la cultura, la moralidad y la política, surge en Europa hacia finales del siglo xVIII, con la diseminación e institucionalización del mercado, la difusión de corrientes filosóficas como el utilitarismo y el individualismo, el surgimiento de la economía política clásica, la consolidación del capitalismo y la consecuente mercantilización de la tierra y el trabajo.

En este proceso ocurre una conversión generalizada de los bienes en mercancías. Otras formas de organización económica, como las sustentadas en la reciprocidad o la redistribución, fueron descalificadas y marginadas. Se asume una actitud instrumental hacia la naturaleza y las comunidades, lo que conduce a su expoliación y explotación, y a la devaluación o destrucción de las actividades de subsistencia. En el proceso se degrada la naturaleza, considerada al servicio exclusivo del hombre, se explota a los trabajadores y se eliminan formas alternas de conocimiento (Escobar, 1999: 58-59). Para ello, y en aras de la eficiencia, la funcionalidad y una racionalidad consecuente, es necesario normalizar, regular y ordenar los espacios, de tal forma que puedan ser sometidos a miradas científicas, a reingeniería social $\mathrm{y}$, en general, al ordenamiento y la planificación.
La homogeneización de los paradigmas y sueños compartidos ha constituido un elemento importante para la ordenación y apropiación de los países económicamente menos avanzados por parte de las áreas desarrolladas.

Las políticas de la segunda posguerra mundial, las decisiones de Bretton Woods y la reciente introducción del concepto de desarrollo, entendido como crecimiento económico, impulsaron cambios muy dinámicos en el país. En este sentido son esclarecedores documentos emitidos desde el poder como la doctrina de "trato justo" del presidente Truman o los preparados por expertos de las Naciones Unidas para diseñar políticas de desarrollo económico de los países subdesarrollados:

Hay un sentido en el que el progreso económico acelerado es imposible sin ajustes dolorosos. Las filosofías ancestrales deben ser erradicadas; las viejas instituciones sociales tienen que desintegrarse; los lazos de casta, credo y raza deben romperse; y grandes masas de personas incapaces de seguir el ritmo del progreso deberán ver frustradas sus expectativas de una vida cómoda. Muy pocas comunidades están dispuestas a pagar el precio del progreso económico (Naciones Unidas, 1951, citado por Escobar, 1999: 34).

En Colombia, el anhelado crecimiento económico y los procesos encaminados a generar riqueza se sustentaron en la explotación de los recursos

172 Ramón Alberto Serna Isaza 
naturales y en la apertura de la frontera agrícola. En consecuencia, se adelantaron programas de exploración minera y petrolera, se abrieron vías $\mathrm{y}$ se mejoró la infraestructura de servicios para incorporar áreas selváticas a la economía, urbanizar nuevas áreas, promover la industrialización, la ganadería y la consecuente 'potrerización', la sustitución de importaciones y la exportación como modelos de desarrollo, con gran degradación de los ecosistemas.

Se trata, entonces, de reproducir características de las sociedades "avanzadas": altos niveles de urbanización e industrialización, tecnificación de la agricultura, incremento en la producción y consumos materiales, adopción de valores culturales y educativos modernos. En consecuencia, se propone la reestructuración de las sociedades "subdesarrolladas"; es decir, transformar de manera drástica dos terceras partes del mundo hacia objetivos de prosperidad material y progreso económico, voluntad que se hace hegemónica en los círculos de poder desde la década de los cincuenta del siglo $\mathrm{xx}$; el discurso del desarrollo se convierte en certeza en el imaginario social y coloniza la realidad. En la práctica se revelan posiciones empiricistas y objetivistas, que dictaminan que esta realidad recién creada, el Tercer Mundo y su gente existen "allá afuera" para ser intervenidos desde el exterior y conocidos mediante teorías propias de la modernidad (Escobar, 1999: 34-40). Bajo esta desigualdad en el poder se construye el discurso colonial como

... aparato que pone en marcha simultáneamente el reconocimiento y la negación de las diferencias raciales/culturales/históricas. Su función estratégica predominante es la creación de un espacio para una "población sujeto", a través de la producción de conocimientos en términos de los cuales se ejerce la vigilancia y se incita a una forma compleja de placer/displacer[...] El objetivo del discurso colonial es interpretar al colonizado como una población compuesta por clases degeneradas sobre la base del origen racial, a fin de justificar la conquista y de establecer sistemas de administración e instrucción[...] Me refiero a una forma de gubernamentalidad que, en el acto de demarcar una "nación sujeto", se apropia de sus diversas esferas de actividad, las dirige y las domina (Bhabha, 1990, citado por Escobar, 1999: 41-42).

Este discurso, basado exclusivamente en un sistema de conocimiento occidental, ha generado un aparato muy eficiente de conocimiento y ejercicio del poder sobre el Tercer Mundo, constituye uno de los rasgos esenciales del desarrollo (Slater, 1993, citado por Escobar, 1999: 42) e implica una producción social del espacio ligada a la consolidación de diferencias, órdenes sociales y subjetividades y la descalificación de formas de conocimiento diferentes, con otras racionalidades no economicistas y reduccionistas (Escobar, 1999: 42-47). Sin embargo, 
a pesar de los cambios recientes en la geopolítica, que han originado las geografías posmodernas, es aún fuerte la relación que se da entre geografía, historia y modernidad en el Tercer Mundo (Soja, 1993, citado por Escobar, 1999: 42), y continúa ejerciendo gran influencia en el imaginario.

Aunque el desarrollo ha sido conceptualizado de diversas formas (ver, p. ej., Serna Isaza, 2001), las premisas implícitas en el discurso dominante del desarrollo sostenible, que plantean un uso eficiente de los cada vez más escasos "recursos" de la naturaleza, con un valor "monetario" sujeto de ser "poseído" y como tal expuesto a las normas reguladoras del mercado, conducen a la propuesta lógica de la privatización de los recursos naturales. Así, el sistema de precios cobijaría toda la naturaleza, agua, aire, genes, suelos, etc., e incitaría a pensar que la "calidad" de la vida se mide en términos de productos materiales (Lewis, 1955; Escobar, 1999: 78-80).

El desarrollo ha sido legitimado a través de las técnicas y las prácticas de la planificación, como aplicación del conocimiento técnico-científico al ámbito de lo público, bajo la creencia de que el cambio social puede ser dirigido y manipulado a voluntad de los agentes planificadores (Estados, municipios, ONG, Corporaciones Autónomas Regionales, etc.), lo cual se logra a través de la estandarización y normalización de la realidad, lo que implica manipulación de las rugosidades para disminuir/desaparecer la diversidad o las diferencias.

La primera "misión" enviada por el Banco Mundial a un país "subdesarrollado", Colombia, en 1949, consideró que el desarrollo y la planificación constituirían la salvación del país, merced a su ingreso al mundo neutral y universalmente deseado de la ciencia y la planificación. En la forma discursiva del documento, se omite toda la historia de colonialismo como factor de consolidación, al afirmar que "la confianza en las fuerzas naturales no ha producido los resultados más felices" (International Bank for Reconstruction and Development, 1950, citado por Escobar, 1999: 61).

Iniciativas como la Alianza para el Progreso, liderada por el presidente Kennedy, que tantas implicaciones ha tenido en la planificación en nuestro país a partir de la década de los sesenta, específicamente en los Planes de Desarrollo, ven en la forma de habitar únicamente algo a ser transformado por la planificación:

El mundo es muy diferente ahora. Pues el hombre tiene en sus manos mortales el poder de abolir todas las formas de pobreza humana y todas las formas de vida humana [...] A aquellos pueblos en las chozas y en las aldeas de la mitad del planeta que luchan por romper las trabas de la miseria masiva [...] les ofrecemos una promesa especial -convertir nuestras buenas palabras en buenas acciones- 
en una nueva alianza para el progreso, para ayudar a los hombres libres y a los gobiernos libres a despojarse de las cadenas de la pobreza (Kennedy, s.f., citado por Escobar, 1999: 62-63).

Los planteamientos de muchas entidades, como el Banco Mundial, logran un adecuado funcionamiento del poder, a través de la invisibilización de los procesos culturales de los campesinos y la generación de realidades ajenas a ellos, como se propone a través del desarrollo rural integrado:

.. es una estrategia diseñada para mejorar la vida económica y social de un grupo específico de personas: los pobres rurales. Involucra la extensión de los beneficios del desarrollo a los más pobres entre aquellos que buscan su subsistencia en las áreas rurales. Una estrategia de desarrollo rural debe reconocer tres puntos. En primer lugar, la tasa de transferencia de gente de la agricultura de baja productividad a ocupaciones más rentables ha sido lenta [...] En segundo lugar [...] la situación empeorará si la población crece a tasas sin precedentes [...] En tercer lugar, las áreas rurales tienen fuerza de trabajo, tierra y por lo menos algún capital que, si se movi- liza, podría reducir la pobreza y mejorar la calidad de vida [...]. [El desarrollo rural] está claramente diseñado para incrementar la producción y elevar la productividad. Tiene que ver con la monetización y la modernización de la sociedad y con su transición del aislamiento tradicional hacia su integración a la economía nacional (Banco Mundial, 1975, citado por Escobar, 1999: 66).

El discurso de la planificación intentará abolir la historicidad de las comunidades, para lo cual se invisibilizan e inviabilizan sistemas de vida completos, a través de perspectivas disciplinares lideradas por expertos que buscan transformar la cultura y sociedad rurales en factores y agentes eficientes de los sistemas productivos por imponer. Se busca compartimentalizar la vida.

La aceptación del desarrollo sostenible como una meta para el país ha implicado la incorporación de lo ambiental en la planificación del desarrollo ${ }^{8}$, a través de las corporaciones autónomas, entidades ambientales y demás entes administrativos relacionados. Sin embargo, la planificación continúa siendo orientada desde afuera y condicionada a criterios de aprobación de la banca internacional.

8 En este aspecto es importante señalar la creación de las Corporaciones Autónomas Regionales, desde finales de la década de 1950; la del Instituto para la Defensa de los Recursos Naturales Renovables y del Medio Ambiente (INDERENA), en 1968, y desaparecido a principios de la década de 1990; la promulgación del Código de los Recursos Naturales en 1974 y de la Ley 99 de 1993, con la que se crea el Ministerio del Medio Ambiente (fusionado actualmente con Vivienda y Ordenamiento Territorial), se organiza el Sistema Nacional Ambiental y se dictan disposiciones en torno al medio ambiente y su gestión. A nivel regional, las directrices ambientales dentro de los Planes de Ordenamiento Territorial están regidas por las Determinantes Ambientales (p. ej., Resolución CAR 1080 de 1998). 
6.5 La transformación ambiental: ¿un problema estrictamente ecosistémico?

Desde las concepciones dominantes se ha entendido la transformación ambiental como cambios en el funcionamiento y en la estructura de los ecosistemas naturales, que son reemplazados por ecosistemas de origen antrópico completamente diferentes; estos conllevan modificaciones en la oferta ambiental e implican su mantenimiento artificial, para evitar que ocurra un retorno al ecosistema original; sin embargo, cuando ocurren cambios muy fuertes, las transformaciones son irreversibles e implican un grave deterioro de las funciones ecosistémicas (Márquez, 2001: 326). En esta perspectiva, lo ambiental se hace equivalente a lo ecosistémico y las transformaciones ambientales son operativizadas básicamente a través de cambios ocurridos en los ecosistemas, evaluando su estado a través de la cobertura de la vegetación, como ha sido propuesto a nivel internacional (IGBP, 1997, citado por Márquez, 2001: 331).

El cambio es conceptualizado implícitamente como negativo, ya que el ideal ecosistémico es asumido como autoequilibrante y estable y la acción humana afectaría inevitablemente dicho balance; el hombre es expulsado de la naturaleza y se torna en agente externo a esta.

Como explicación general de los cambios ecosistémicos acaecidos en
Colombia desde el periodo de la conquista, Márquez (2001: 323-480) identifica dos fuerzas directrices de la transformación. La primera está relacionada con la satisfacción de las necesidades básicas de tipo económico y social, a través del aprovechamiento de los recursos naturales y la producción de materias primas o alimentos. La segunda busca el control social de la mano de obra necesaria para explotar y apropiar recursos y tierra. Se plantea algún tipo de relación entre la abundancia de recursos naturales, asociada con los ecosistemas colombianos, su destrucción y apropiación, y la actual situación política y social del país.

En esta visión desarrollista, los recursos naturales que se pierden deben ser sustituidos (y son sustituibles) con excedentes de producción generados en actividades agropecuarias y agrícolas en las áreas transformadas, aunque en muchas ocasiones el deterioro ecosistémico implica mayores costos de producción (Márquez, 2001: 347). Como se observa, estos planteamientos coinciden con un neoliberalismo sustentable o de sustentabilidad débil, fundamentado en la posibilidad de sustitución completa del capital natural por otros tipos de capital (Serna Isaza, 2001: 143).

A medida que se hace visible el impacto económico, social y político generado por la desestabilización de los ecosistemas, surge la tendencia conservacionista, para preservar relictos arqueológicos de los paisajes, 
esencialmente naturales, a través de Reservas, Parques Nacionales, Santuarios, etc. Cuando la naturaleza fragmentada es incorporada como base de las necesidades utilitarias de los grupos humanos, surge el planteamiento de la Estructura Ecológica Principal. De esta manera se empobrece y objetiviza la dialéctica con la naturaleza: adaptación y adecuación son planificados desde la ingeniería. Se olvida la historicidad de estas relaciones y se llega al extremo de plantear que "las mentalidades tienden a consagrar visiones del entorno que dificultan la comprensión de los cambios que en él ocurren, impidiéndole reaccionar oportunamente a dichos cambios" (Márquez, 2001: 443), sin notar que los procesos de desarrollo económico desplazan comunidades autóctonas a nuevos sitios, en los que necesariamente afectarán el ambiente. Se niegan otras formas de elaboración étnica y cultural, diversas revitalizaciones o innovadores sincretismos. La pobreza es estigmatizada como fuente de la degradación ecosistémica, y no los modelos de vida que han acompañado al colonialismo y al desarrollo.

Ampliando y trascendiendo esta visión estrictamente ecosistémica, y de gran relevancia para el presente ensayo, podría decirse, siguiendo los planteamientos posestructuralistas de Cronon, que en las temáticas de "historia ambiental se plantea la tarea de incluir dentro de sí algo más del mundo no humano que la mayoría de otras historias y, a pesar de esto, los agentes hu- manos continúan siendo las principales anclas para sus narrativas" (2002: 56). El agente humano pasa de ser variable exógena en el enfoque ecologista, a protagonista y antagonista, a persona y comunidad, a forjador de historias, narrativas y espacios, y es relevante el significado de la naturaleza para el ser humano. En un proceso dialéctico, la naturaleza será coautora, un poco sui generis, por faltarle una voz claramente propia, pero difícilmente silenciosa, ya que cuando describimos las actividades humanas dentro de un ecosistema, estas tienen consecuencias reales sobre la naturaleza, y los eventos naturales tienen consecuencias reales para la gente (Cronon: 61).

Tanto la historia ambiental como la ecología política, como temáticas integradoras de la naturaleza en las ciencias sociales, permiten abordar la relación de los seres humanos con la naturaleza a través de tres ejes fundamentales: la transformación del medioambiente, la influencia de la naturaleza sobre la vida social y la indagación de ideas sobre la naturaleza (Leal, 2002: 123).

\subsection{Al rescate de la naturaleza en lo ambiental: una mirada desde la antropología y los sistemas complejos}

Cuando la teoría liberal dominante ya no convence y el marxismo es lento en su renovación ideológica surgen nuevos espacios dentro de la teoría 
social moderna, como el posestructuralismo, que producen resultados bastante diferentes en cuanto a los modos de acción y a la explicación de lo social. El posestructuralismo sitúa en la base del conocimiento y de la dinámica de lo social el lenguaje y la significación como constitutivos de la realidad, en lugar del individuo/mercado o la producción/trabajo (Escobar, 1999: 21). El materialismo histórico continúa siendo esencial para comprender el mundo capitalista contemporáneo, desde el neoliberalismo a la globalización.

La globalización, al igual que procesos ya iniciados por el capitalismo, la modernidad y el desarrollo, pareciera disminuir el potencial de los lugares para su propia reproducción, esto es, para la configuración de prácticas culturales y normas que rigen la vida social, debido a que sitúan en lo global la capacidad para transformar y crear (Escobar, 1999: 29). Es por ello que en los procesos de reivindicación cultural lo local y sus manifestaciones lugareñas y la dimensionalidad del terruño y sus formas de habitar cobran tanta importancia.

A pesar de la globalización, las especificidades del lugar se mantienen a través de resistencias, reconversiones o recombinaciones. Por ello, diversos autores plantean la defensa del lugar como proyecto político, teórico y ecológico (Escobar, 1999: 29), manifiesta en la defensa de prácticas ecológicas, culturales y económicas que derivan en estrategias alternativas de sostenibilidad y desarrollo, en resistencia a la mercantilización de la biodiversidad y a los productos transgénicos, con lo que se defiende la naturaleza, el cuerpo y la alimentación como práctica de lugar, lejana a la normatización impuesta por la modernidad capitalista. La etnografía ecológica también hace valiosos aportes de modelos locales de naturaleza. Incluso el ciberespacio puede permitir prácticas políticas para la defensa del lugar (ver, p. ej., Escobar, 1999: 29; Suárez Moreno, 2000: 124-138).

Se cuestiona la forma en que la práctica antropológica ha hecho lecturas culturales, como si se tratara de objetos o textos aislados, y se propone buscar "nuevas maneras más sutiles y concretas de escribir y leer otras culturas [...] nuevas concepciones de la cultura como hecho histórico e interactivo" (Clifford \& Marcus, 1986, citado por Escobar, 1999: 50-51).

Las formas de conocimiento y las prácticas alternativas, que no son ni tradicionales ni modernas, pueden suministrar nuevas formas de concebir el cambio social, de organizar sociedades y economías, de pensar y actuar, de curar y vivir, lo que implica abrir la racionalidad occidental a formas plurales de vida (Escobar, 1999: 73). La propuesta culturalista plantea rescatar el valor de la naturaleza como ente autónomo, como fuente de vida -tanto material como espiritual-, ya que ha dejado en gran parte de ser un 
actor social importante en el discurso del desarrollo sostenible. La naturaleza desaparece inevitablemente con el desarrollo de la sociedad industrial y se transforma en "ambiente". Ya no circula la vida, sino materias primas, recursos, contaminantes, productos industriales. Asistimos a la muerte simbólica de la naturaleza, al tiempo que ocurre su degradación física (Sachs, 1992b, citado por Escobar, 1999: 84).

Sin embargo, el reconocimiento de múltiples concepciones sobre la naturaleza implica su construcción social, que es transformada de acuerdo con condiciones y situaciones históricas y sociales particulares. Ideas particulares sobre medioambiente, naturaleza o ecología están en interrelación constante con otras nociones, lo cual implica procesos políticos de negociaciones y conflictos. Por ello, los cambios ambientales no pueden ser neutros, ya que los beneficios y costos de la naturaleza, vista como recurso, estarán mediados por relaciones desiguales de poder (Ulloa, 2002: 139).

Así, por ejemplo, en el discurso de la biodiversidad la naturaleza es vista como reserva de valor en sí misma, valor que debe ser liberado para el capital y, en teoría, para las comunidades, que lo han cultivado por medio del conocimiento científico y la biotecnología. Bajo esta perspectiva de reserva de capital para ser privatizada y explotada, las comunidades autóctonas -indígenas y campesinas- están siendo reconocidas como dueñas de sus territorios (o de lo que queda de ellos), al tiempo que las entidades internacionales promueven la protección intelectual de la materia viva. Los "conocimientos tradicionales" constituyen un elemento importante en la conquista científica de la biodiversidad, aunque los biólogos y demás expertos involucrados no perciben que dicho conocimiento está estructurado en torno a complejas construcciones culturales que implican profundos procesos históricos y relacionales y no los objetos en sí mismos (Escobar, 1999: 88-89, 95).

Actualmente, las nuevas biotecnologías son privilegiadas por la dinámica del capital, al agregar valor a la naturaleza mediante la investigación científica, que convierte al genoma en parte de las condiciones de producción. Aunque es posible hablar de "naturaleza orgánica", en sociedades premodernas; "naturaleza capitalizada", en las modernas, y "naturaleza construida", en las posmodernas, para el ser humano no existe naturaleza fuera de la historia y, por lo tanto, desde esta consideración todas serían construidas. Los tres regímenes mencionados coinciden históricamente hoy en el mundo (Escobar, 1999: 97).

Desde una perspectiva ecosocialista, el discurso del desarrollo sostenible pretende la sustentabilidad del capital, no de la naturaleza; el culturalismo plantea que la apuesta es a la sustentabilidad de la cultura occidental (Escobar, 1999: 89). 
El ecosocialismo ha propuesto perspectivas integradas que consideran aspectos ecológicos, culturales, productivos y tecnológicos. El discurso ambientalista propuesto desde el ecosocialismo busca cambios sociales e institucionales que permitan refuncionalizar la racionalidad económica dominante, con el fin de contener sus efectos ecodestructivos, a través de la incorporación de la lógica de los procesos naturales en los mecanismos del mercado, y, de esta manera, asegurar un desarrollo sustentable y sostenido (Leff, 1994: 34-35).

Las comunidades locales están hoy abocadas a experimentar nuevas formas alternativas de producción y organización y, al mismo tiempo, a practicar formas de resistencia cultural y semiótica a la reestructuración que opera en la fase ecológica de la naturaleza por conducto de la ciencia y el capital (Escobar, 1999: 91). Se plantea la posibilidad de diseñar estrategias científicotecnológicas que permitan utilizar la creatividad local y la integración de tecnologías nuevas a las existentes, a través de un pluralismo tecnológico, así como lograr el acceso a tecnologías novedosas por poblaciones marginadas (Gallopín, 1990, citado por Escobar, 1999: 95). En definitiva, deben realizar mediaciones e hibridaciones con los discursos y prácticas del capital y la modernidad.

\section{Hacia una geohistoria ambiental}

Cada sociedad organiza de manera particular el territorio en el espacio que domina, lo que se refleja en la distribución de la gente, de las infraestructuras, de los lugares de producción y de los diversos tipos de flujos. Así, el espacio, como producto social, representa un modo de existencia de las sociedades, producido y organizado en un movimiento constante de transformación, de manera similar a la evolución de la sociedad que ocupa ese espacio. Este proceso no se produce en autonomía de las condiciones sociales, económicas o del medio. Por ello, la construcción social del espacio refleja los diversos intereses y sus conflictos y exige el análisis de los actores, ya que todos ellos (Estado, comunidades, grupos sociales, individuos) actúan en un sistema complejo de interacciones que ocurren en diversas escalas (local, regional, nacional, internacional). Así mismo, el espacio es memoria y su organización es resultado de experiencias históricas. Por ello es conveniente entender cómo ha surgido, se ha estructurado y reestructurado dicho espacio (Zambrano Pantoja, 2000).

Con el fin de abordar el asunto de los cambios acontecidos, es viable y pertinente la propuesta de Milton Santos de que "el espacio sea definido como un conjunto indisoluble de sistemas de 
objetos y sistemas de acciones" (2000: 18), lo cual permitirá reconocer las categorías analíticas internas, como el paisaje, la configuración territorial, el espacio producido o productivo, la división territorial del trabajo, las formas-contenido y las rugosidades. El estudio dinámico de dichas categorías supone reconocer algunos procesos básicos que, en principio, son externos al espacio: la técnica, la acción, los objetos, la norma y los acontecimientos, la idealización y la objetivación, los símbolos y la ideología, la universalidad y la particularidad, la totalidad y la totalización, la temporalización y la temporalidad (Santos, 2000: 18-19).

La principal forma de relación entre el hombre y la naturaleza o, mejor, el ambiente viene dada por la técnica. Esta constituye un conjunto de medios sociales e instrumentales con los cuales el hombre, en el proceso de realización de su vida, produce y crea espacio (Santos, 2000: 27). Por ello, "el hombre, ese creador de paisajes, solamente existe porque es miembro de un grupo que en sí mismo es un tejido de técnicas", técnicas de producción y técnicas de organización (Gourou, 1973, citado por Santos, 2000: 30-31). Su noción se extiende a todos los dominios de la actividad humana relacionados con la industria y el arte (Sorre, 1948: 5, citado por Santos, 2000: 31).
La técnica ha sido definida como "toda una serie de acciones que comprenden un agente, una materia y un instrumento de trabajo o medio de acción sobre la materia, y cuya interacción permite la fabricación de un objeto o de un producto" (Roca, 1989, 120, citado por Santos, 2000: 34).

Para incorporar la técnica como base de la explicación geográfica es posible considerarla como un medio en sí misma, convirtiéndola en objeto técnico. De esta forma, incluso los objetos naturales pueden ser considerados objetos técnicos, al ser tenido en cuenta el posible uso. Su adopción social dependerá de una evaluación de los valores técnicos que puedan conducir a éxito o fracaso (Santos, 2000: 34).

Las técnicas son difundidas desigualmente y se implantan selectivamente en el espacio, forman parte de él, de tal forma que en una misma porción del territorio conviven elementos técnicos de diversas épocas. La adopción de una técnica específica dependerá de su compatibilidad con estructuras pertenecientes a un sistema precedente?. La combinación de sistemas técnicos de diferentes edades tendrá consecuencias sobre las posibles formas de vida en las áreas involucradas. Desde la perspectiva de la técnica dominante, los residuos del pasado se constituyen en obstáculos para la difusión de lo nuevo o plantean

Sin embargo, en los procesos de conquista, apropiación y más recientemente planificación del desarrollo, esto se logra compulsoriamente a través de procesos continuados de aculturación, como se ha puesto de relieve en apartados anteriores. 
el problema de encontrar formas que, a pesar de ello, permitan acciones simultáneas. Esto implica que la aceptación de las técnicas es incompleta y relativa. Sin embargo, en la fase actual del proceso de globalización existe una voluntad para la dominación mundial sustentada por una sinergia entre un uso ciego de la tecnología y las grandes organizaciones, que evita la homogeneización del espacio, debido a las especificidades de los territorios y las contingencias del "medio asociado" (Santos, 2000: 3841).

La técnica revela la geohistoria de los espacios:

Toda situación es una construcción real que admite una construcción lógica, cuyo entendimiento pasa por la historia de su producción. El recurso a la técnica debe permitir identificar y clasificar los elementos que construyen tales situaciones. Estos elementos son datos históricos y toda técnica incluye historia. En realidad, toda técnica es historia engastada. A través de los objetos, la técnica es historia en el momento de su creación y en el de su instalación, y revela el encuentro, en cada lugar, de las condiciones históricas (económicas, socioculturales, políticas, geográficas), que permitieron la llegada de esos objetos y presidieron su operación. La técnica es tiempo congelado y revela una historia (Santos, 2000: 42).

Por lo tanto, la técnica ayuda a historizar, esto es, a considerar el espacio como fenómeno histórico y a geografizar, es decir, "producir una geografía como ciencia histórica" (Santos, 2000: 43). Se plantea entonces el problema epistemológico de la geografía, basado en una búsqueda que permita sistematizar las relaciones de la técnica con el espacio y con el tiempo.

De acuerdo con los planteamientos anteriores, cobra gran importancia la visión de historicidad de los paisajes, entendido lo geohistórico como sucesión integrada de presentes (Tovar, 1996: 17-30), que constituyen manifestación externa de contenidos subyacentes. Se genera una arqueología del paisaje (Molano Barrero, 1995: 1-10), que busca integrar los ordenamientos espaciales actuales con los heredados -que mantienen una fisonomía propia como entidad espacial-, y los procesos ordenadores socio-espaciales que lo han precedido. Por ello se plantea la necesidad de un conocimiento adecuado de la evolución de la sociedad, su cultura y las relaciones entre estas (Sayer, 2000, citado por Bonilla Godoy, 2001: 131).

La vida cotidiana, a pesar de estar constituida por actividades mayoritariamente rutinarias, en las que cabe poca elección, también está determinada por decisiones deliberadas, infrecuentes, pero cruciales y de efectos duraderos, como formar una familia, cambiar de residencia, escoger un trabajo, etc. Estas decisiones condicionan el contexto de la vida cotidiana, el habitar, y constituyen los elementos

182 Ramón Alberto Serna Isaza 
clave en torno a los cuales se estructura el ritmo de actividades diarias, como ha sido planteado por el modelo espacio-temporal de la rutina y la elección deliberada, desarrollado en la Universidad de Londres (Cullen y Godson, 1975; Cullen, 1978, citados por Díaz Muñoz, 1992: 15-44).

Un avance significativo en la unificación espacio-temporal fue logrado por Hägerstrand en su Geografía del Tiempo, mediante la 'congelación' de los acontecimientos en patrones gráficos que permiten reconocer las relaciones mutuas entre los componentes de la organización social, su base física y la dinámica de dicha relación. Con el propósito de conocer la incidencia de los procesos sociales, económicos o políticos generales en la vida cotidiana de individuos y grupos, tiene en consideración un enfoque contextual y multiescalar, que permite analizar la actividad de los individuos o grupos en relación con su entorno (Díaz Muñoz, 1992: 15-44).

El sistema de objetos y el sistema de acciones que definen el espacio pueden ser críticamente integrados en la intencionalidad. Bajo esta perspectiva, en la Geografía del Tiempo de Hägerstrand no es el estudio de la actividad real de los individuos lo que interesa, sino el estudio de las condiciones para la actividad potencial que puede darse en una situación espacio-temporal específica. El paisaje manifestaría de manera extrema dicha intencionalidad (Díaz Muñoz, 1992: 15-44).
El punto de partida será la sociedad humana en proceso, realizándose sobre una base material: el espacio, el tiempo y su uso, los diversos aspectos de las acciones, la materialidad y sus diversas formas. Con ello se empiriza el tiempo, se hace material y se asimila al espacio, que cobra existencia con la materialidad.

La técnica entra aquí como un rasgo de unión, histórica y epistemológicamente. Las técnicas nos dan, por un lado, la posibilidad de empirización del tiempo y, por otro, la posibilidad de una calificación precisa de la materialidad sobre la que trabajan las sociedades humanas. Por tanto, esa empirización puede ser la base de una sistematización solidaria con las características de cada época. A lo largo de la historia, las técnicas se dan como sistemas, diferentemente caracterizadas [...] [y son] una medida del tiempo: el tiempo del proceso directo del trabajo, el tiempo de la circulación, el tiempo de la división territorial del trabajo y el tiempo de la cooperación (Santos, 2000: 47).

La edad histórica de una técnica se da con su incorporación y redefinición por una sociedad en un lugar específico, en el que confluirán diversas técnicas acogidas en diferentes momentos y cuyos efectos estarán a su vez condicionados por el de otras técnicas preexistentes.

Debido a que la acepción de medio sobrepasa ampliamente la de entorno natural, las nociones de técnica y 
medio son inseparables, ya que cada nuevo objeto es apropiado de forma específica por el espacio preexistente: "Es el espacio el que determina los objetos: el espacio visto como un conjunto de objetos organizados según una lógica y utilizados (accionados) según una lógica [...] [que] se confunde con la lógica de la historia, a la que el espacio asegura la continuidad” (Santos, 2000: 36).

\subsection{Paisajes, sistemas de alteridad y la cuestión ambiental}

El paisaje, como concepto integrador, ha trasegado desde visiones originariamente pictóricas de la naturaleza como ente autónomo, según se comentó en apartados anteriores, a la aplicación de conceptos biológicos, geomorfológicos y ecológicos al territorio, hasta lograr la incorporación del paisaje humano o humanizado.

Como tal, el paisaje puede ser conceptualizado por "el conjunto de formas que, en un momento dado, expresa las herencias que representan las sucesivas relaciones localizadas entre hombre y naturaleza" (Santos, 2000: 86) y estará caracterizado por "una determinada distribución de formas-objetos, provistas de un contenido técnico específico" (Santos, 2000: 87). Debido a que esta relación dialéctica es cambiante en el espacio-tiempo, es asimétrica la valoración-percepción social de ellos. En consecuencia, para comprender cualquier paisaje, subyace en todo momento el conocimiento de su historia.
El paisaje no es solo un lugar, sino también su imagen, y reside no solo en la naturaleza, en la historia, en la estructura social, sino también en la cultura (Martínez de Pisón, 1998: 17), constituyendo así un importante patrimonio. Como imagen cultural, el paisaje representa una traducción ordenada de la realidad, a la que se atribuyen valores, dimensiones simbólicas y significados (Ortega Cantero, 1998: 137).

Entender el paisaje implica seguir la doble vía cognoscitiva de la explicación y la comprensión. Para explicar el paisaje, dimensión más sistémica y formalizable, se tienen en cuenta las unidades de paisaje, se caracterizan las formas, los nexos causales, su localización y se establecen comparaciones. La comprensión busca captar el sentido del paisaje, a través de procesos de compenetración y simpatía, mediante planteamientos frecuentemente fenomenológicos y hermenéuticos (Ortega Cantero, 1998: 145-146).

El paisaje, como lugar del sentido, se apoya en dos aspectos complementarios: la analogía, que evita las visiones analíticas fracturadoras de la realidad y permite entender el sistema de relaciones como un conjunto de correspondencias, y la subjetividad, cuyo ejercicio implica razón, inteligencia, sentimiento, imaginación y capacidad creadora para entender el sentido del mundo. De esta manera, el conocimiento dejará de ser un acto mecánico e impersonal, para constituir un empeño holístico en pos de entender el sentido del mundo (Ortega Cantero, 1998: 141-145). 
Alteridad hace alusión a la formación de paisaje desde la relación hombre-naturaleza. El sistema de alteridad es la unidad estructural-funcional del paisaje humanizado y denota una forma típica de relación entre un grupo humano y su entorno, según propiedades y componentes de sistemas abiertos autoorganizativos y autorreplicantes. Implica, por lo tanto, la adecuada incorporación de información, materia y energía al crecimiento y reproducción de su estructura y función. En estos sistemas, las variaciones están teleológicamente direccionadas por la percepción cultural de las necesidades $\mathrm{y}$, debido a su naturaleza cultural, permiten incorporar información de modelos fallidos (Fundación Bacha-queros, inédito). En el cuadro 1 se listan algunos elementos que se han empleado para el estudio de los sistemas de alteridad.

\section{Cuadro 1}

Elementos para la caracterización y modelación de sistemas de alteridad

\begin{tabular}{|c|c|c|}
\hline Unidad estructural-funcional & \multicolumn{2}{|c|}{ Propiedades y componentes } \\
\hline Entorno relevante & \multicolumn{2}{|c|}{$\begin{array}{l}\text { Elementos y procesos determinantes } \\
\text { Elementos y procesos afectados }\end{array}$} \\
\hline Entorno subjetivo & \multicolumn{2}{|c|}{$\begin{array}{l}\text { Ideas ordenadoras } \\
\text { Representación simbólica } \\
\text { Modelos de percepción y decisión } \\
\text { Comunicación social de la alteridad }\end{array}$} \\
\hline Estructura & \multicolumn{2}{|l|}{$\begin{array}{l}\text { Espacial } \\
\text { Temporal } \\
\text { Social }\end{array}$} \\
\hline Flujos & \multicolumn{2}{|l|}{$\begin{array}{l}\text { Materia } \\
\text { Energía } \\
\text { Capital } \\
\text { Información } \\
\text { Afecto }\end{array}$} \\
\hline Ontogenia & \multicolumn{2}{|c|}{$\begin{array}{l}\text { Establecimiento } \\
\text { Crecimiento (cambios cuantitativos) } \\
\text { Desarrollo (cambios cualitativos) } \\
\text { Adaptación (fenotípica) } \\
\text { Adecuación (retroalimentación al medio) } \\
\text { Reproducción } \\
\text { Decadencia }\end{array}$} \\
\hline Sucesión & $\begin{array}{l}\text { Colonización } \\
\text { Expansión } \\
\text { Agregación } \\
\text { Consolidación }\end{array}$ & $\begin{array}{l}\text { Asociación } \\
\text { Facilitación } \\
\text { Competencia } \\
\text { Segregación } \\
\text { Sustitución }\end{array}$ \\
\hline Evolución & \multicolumn{2}{|l|}{$\begin{array}{l}\text { Reproducción } \\
\text { Transmisión } \\
\text { Variación } \\
\text { Selección } \\
\text { Especialización }\end{array}$} \\
\hline
\end{tabular}

Fuente: fundación Bachaqueros (inédito). 
Aunque este enfoque ha sido poco explorado en los procesos de planificación, es importante determinar los factores y elementos ambientales que conforman el entorno relevante, los cuales tienen un efecto determinante sobre el desarrollo del sistema de alteridad.

La cuestión ambiental parte del supuesto de que ha sido generada y está comprometida por un conjunto de procesos sociales, y es por lo tanto una problemática social (Leff, 1994: 19), cuyo análisis se orienta en una perspectiva constructivista que tiende a fundamentar, analizar y promover procesos de transición a nuevas racionalidades sociales, en las cuales incorpora las condiciones ecológicas y sociales para promover un desarrollo equitativo, sustentable y sostenible (Leff, 1986, citado por Leff, 1994: 21).

El movimiento ambientalista que se inició en la década de los sesenta ha mostrado de manera patente que existe un límite para ciertas actividades económicas en términos de persistencia biofísica y de resiliencia de los sistemas planetarios. Por lo tanto, hay un componente físico o tecnológico, dentro del cual la tecnología y el conocimiento humano permiten gran variedad de ajustes. Plantea un determinismo a escala global, mientras que las escalas locales estarían marcadas por las virtudes del posibilismo. Sin embargo, los desarrollos tecnológicos del hombre pueden ocasionar, bajo suficiente energía disponible, el reem- plazo de alguno de los sistemas biofísicos por otros hechos por el hombre. Este es el nuevo determinismo de los ambientalistas (Simmons, 1990: 6).

Los movimientos ambientales involucran un amplio rango de intereses y objetivos, pero la división ecocentrismo/tecnocentrismo, formalizada por O'Riordan (1981, citado por Bayliss-Smith \& Owens, 1994: 117), ha suministrado un marco analítico perdurable. El ecocentrismo está asociado con una perspectiva no utilitaria del mundo natural, con énfasis en la bioética, el antimaterialismo, el rechazo a la noción de ciencia 'objetiva' y su poca fe en el 'ajuste técnico'. En contraste, el tecnocentrismo ve el incremento en bienes materiales como universalmente deseable, y al cual se puede acceder mediante un buen manejo de recursos (planificación). Proponen un mundo en el que la ciencia, 'libre de valor', y la tecnología aseguran un potencial casi infinito para utilizar recursos naturales al servicio de la humanidad.

Bajo estas posiciones contrastantes, el movimiento ambientalista, como un todo, no puede ser identificado con ninguna ideología política, ni con la división tradicional de izquierda-derecha. Sus militantes, con frecuencia, claman que los temas verdes trasciendan de alguna forma a otras ideologías políticas y se perciben como ecocentristas, ya que representan todo un nuevo paradigma, y como tecnocentristas, ya que tienden a ver los problemas ambientales como 
políticamente neutros (Bayliss-Smith \& Owens, 1994: 118).

Actualmente, el discurso de muchos entes planificadores, desde la perspectiva del Paisaje, la Teoría General de Sistemas y la Complejidad, considera el territorio idealmente caracterizado por la confluencia de múltiples procesos que al interrelacionarse van a constituir la estructura de un sistema que funciona como una totalidad organizada (ver, p. ej., García, 1994; Capra, 1998; Morin, 2001). El análisis sistémico toma en consideración el contenido, la configuración, la estructura, el funcionamiento y el comportamiento del sistema territorial o "geosistema" (Muñoz Jiménez, 1998: 46).

En este sentido, conocer, describir y comprender las transformaciones ambientales implica abordar los patrones espaciales de organización (forma, orden, cualidad); las estructuras sistémicas (sustancia, materia, cantidad) y los procesos que constituyen el vínculo entre estos. Se entiende como patrón de organización la configuración de las relaciones entre los componentes del sistema, las cuales definen sus características esenciales. Estos patrones forman redes en las que cada componente participa en la producción o transformación de otros componentes de dicha red, en un proceso continuo de autoconstrucción, patrón conocido como autopoiesis. La estructura es la manifestación física de dicho patrón de organización. Así, mientras la descripción del patrón implica una cartografía abstracta de relaciones, la de la estructura involucra los componentes físicos presentes. Los procesos se manifiestan a través de las actividades comprometidas en la continua construcción física del patrón de organización del sistema (Capra, 1998: 171-181).

Los sistemas abiertos, como estructuras disipativas, incluyen la idea de puntos de inestabilidad que permiten el surgimiento de nuevas estructuras y formas de orden, ya que se mantienen en un estado estable (a lo largo de periodos prolongados de tiempo), lejos del equilibrio. Esto implica que una estructura disipativa de este tipo no sigue ninguna ley universal, sino que es exclusiva del sistema particular, con toda su carga de riqueza y variedad. En los puntos de inestabilidad, el comportamiento del sistema puede tomar una de diversas vías ${ }^{\mathbf{1 0}}$, dirección que dependerá del historial previo del sistema y de diversas condiciones externas, pero que no puede ser pronosticada. Por ello, la indeterminación es otra de las características de los sistemas disipativos (Capra, 1998: 190-204).

Bajo el paradigma dominante del desarrollo y la planificación, los estudios "científicos" del paisaje han estado orientados a la ordenación del

10 A este concepto se refiere la bifurcación, como umbral de estabilidad en el que la estructura disipativa puede derrumbarse o trascender hacia uno o varios estados nuevos de orden (Capra, 1998: 181-184). 
territorio, para lo cual son cada vez más abundantes los estudios de prognosis y de sintéresis.

En la etapa de prognosis se reconocen $\mathrm{y}$ analizan los elementos que estructuran el geosistema y sus interrelaciones. Con estos elementos se procede a diagnosticar el estado actual, con el fin de clasificarlo y determinar su aptitud para acoger alguna función específica. Posteriormente, de acuerdo con estudios de dinámica o evolución del sistema, se puede prever el estado que tendrá en un futuro más o menos próximo, siempre y cuando se cumplan las consideraciones planteadas al emitir el diagnóstico. La última etapa consistirá en llevar a cabo la sintéresis, que consiste en la formulación de una propuesta de actuación para evitar o mitigar consecuencias no deseadas de las actuaciones realizadas sobre el paisaje (Bovet Pla \& Ribas Vilàs, 1992: 123-133). La dialéctica y la historicidad de los paisajes son simplificados hacia una intencionalidad teleológica emanada desde el poder. El discurso de las corporaciones autónomas regionales y otros entes planificadores está signado por las evaluaciones de impacto ambiental, con enfoques prioritariamente hidráulicos y productivos que se concretan en los planes de manejo. Es de esperar que las investigaciones continúen orientadas hacia el mantenimiento y apoyo del sistema social que sufraga los gastos y no hacia investigaciones que hagan patentes las contradicciones que existen en dicha sociedad (Unwin, 1995).
7.1.1 Las evaluaciones de impacto ambiental en los estudios de paisaje. Se entiende por impacto ambiental "el efecto que una determinada acción directa del hombre sobre el medio produce en sus distintos componentes naturales (clima, substrato geológico, morfología superficial del terreno, aguas, suelos, vegetación y fauna)" (Estruch García, 1992: 126). Es claro que el enfoque es estrictamente orientado a la ordenación del medio físico y considera que la relación hombrenaturaleza se da en planos homogéneos, de tal forma que, cuando los efectos resultan inducidos indirectamente por el hombre, se habla entonces de riesgo natural, otro componente importante en los estudios ordenadores del territorio.

Los estudios adelantados por las entidades ambientales son principalmente de carácter descriptivo no integral. En ellos destaca el énfasis que han tenido los estudios de calidad ambiental, en los cuales se valora la importancia naturalística o productiva de algunos elementos naturales del medio, para determinar cuáles son los prioritarios por preservar, y los informes de capacidad de acogida, orientados a determinar una aptitud del medio físico para acoger usos del suelo específicos. La información sesgada, debido a su carácter oligo-dimensional y no integral, es incorporada en la planificación física del territorio, a través de los planes de ordenamiento municipal, y son las determinantes ambientales emanadas de las corporaciones autónomas, 
el sustento técnico a las decisiones ordenadoras.

7.1.2 Paisaje y bioindicación. En el paisaje se concreta la realidad material de la organización ecosistémica, que está constituida por una parte visible de su estructura y composición, el fenosistema, y una parte no visible, el criptosistema (Etter, 1990, citado por Etter, 1994). El fenosistema es, por lo tanto, resultado estructural de procesos y transformaciones en el criptosistema, que responde a determinaciones culturales surgidas de ideas ordenadoras implícitas en la cultura que actúa sobre el territorio. Dentro del fenosistema, la cobertura puede actuar como elemento de síntesis, y la cobertura de la vegetación, al trascender la asociación misma de plantas de un lugar, puede constituir un nivel macrobásico de bioindicación (Zonneveld, 1983, citado por Etter, 1994: 13). Sin embargo, debe tenerse en cuenta que los indicadores de síntesis tienen propiedades de indicación particulares, como se observa en el cuadro 2 .

Aunque todo organismo es indicador del medio en el cual se desarrolla, ya que su existencia implica procesos tanto de adaptación como de adecuación a los factores ambientales, es conveniente señalar algunos aspectos sobre la bioindicación acuática, debido a que

Cuadro 2. Indicadores de síntesis del paisaje

\begin{tabular}{|c|c|c|c|}
\hline & \multicolumn{2}{|c|}{ Aspectos característicos } & Indicación \\
\hline Geoforma & \begin{tabular}{|ll} 
o & Macrorrelieve \\
o & Pendientes \\
o & Patrón de drenaje
\end{tabular} & $\begin{array}{l}\text { - Tipo } \\
\text { - Intensidad/amplitud } \\
\text { - Forma } \\
\text { - Inclinación } \\
\text { - Longitud } \\
\text { - Tipo } \\
\text { - Densidad } \\
\text { - Profundidad de incisión }\end{array}$ & $\begin{array}{l}\text { - Geogénesis } \\
\text { - Paleoclima } \\
\text { - Composición sustrato } \\
\text { - Hidrología } \\
\text { - Procesos geomorfológicos activos } \\
\text { - Procesos geomorfológicos fósiles } \\
\text { - Suelo }\end{array}$ \\
\hline Cobertura & \begin{tabular}{|l} 
o Cobertura vegetal \\
o Coberturas culturales \\
o Coberturas hídricas \\
o Cobertura roca/suelo
\end{tabular} & $\begin{array}{l}\text { - Fisionomía general } \\
\text { - Formas de vida } \\
\text { - Biotipología } \\
\text { - Fenología } \\
\text { - Estratificación de biomasa } \\
\text { - Composición florística } \\
\text { - Tipo de límites } \\
\text { - Patrones culturales } \\
\text { - Patrones espaciales } \\
\text { - Tipo } \\
\text { - Forma }\end{array}$ & $\begin{array}{l}\text { - Clima (macro, micro) } \\
\text { - Hidrología } \\
\text { - Suelo/sustrato } \\
\text { - Actividad humana/uso } \\
\text { - Procesos geomorfológicos activos } \\
\text { - Régimen de perturbación }\end{array}$ \\
\hline
\end{tabular}

Fuente: Etter (1990, citado por Etter, 1994: 14). 
estos son frecuentemente omitidos en los estudios de paisaje.

Se ha considerado indicador biológico acuático aquel cuya presencia y abundancia señala algún proceso o estado del sistema en el cual habita, ya que, aunque soporta los efectos ocasionados por el elemento perturbante, presenta respuestas compensatorias o tolerantes (Pinilla, 1998: 11). Para los ecosistemas acuáticos se plantean como organismos indicadores los organismos saprobios, animales y plantas que están estrechamente ligados a determinadas condiciones de mayor o menor contaminación orgánica.

Se suele emplear un sistema de cuatro niveles para clasificar las aguas saprobias, de acuerdo con los planteamientos desarrollados inicialmente por Kolkwitz y Marsson entre 1902 y 1935; planteamientos que fueron revisados y ampliados por Liebmann, entre 1950 y 1962 (Streble \& Krauter, 1987).

Clase IV, zona polisaprobia. Es la zona más contaminada. El agua contiene un nivel de oxígeno bajo o nulo, despide mal olor, presenta elevadas poblaciones de bacterias y de pocos otros seres vivos que pueden presentar gran proliferación.

Clase III, zona $\boldsymbol{\alpha}$-mesosaprobia. En esta zona, la autodepuración alcanza un nivel en el que predominan los procesos de oxidación. Aunque el agua contiene abundante oxígeno, su consumo es elevado a causa de la activi- dad bacteriana. Aunque son poco frecuentes las plantas y los animales superiores, son numerosas las diatomeas, algas verdes, flagelados y ciliados.

Clase II, zona $\boldsymbol{\beta}$-mesosaprobia. El agua es rica en oxígeno, generalmente clara y disminuye bastante la población bacteriana. Para los lagos, el plancton es rico en especies (diatomeas, algas verdes, dinofla-gelados, rotíferos, microcrustáceos, algas verdes) y en las orillas abunda vegetación herbácea. Presenta una biota más diversa que los niveles anteriores. En esta clase de calidad termina el proceso de autodepuración, objetivo de los procesos de saneamiento hídrico.

Clase I, zona oligosaprobia. El agua es en gran medida pura, rica en oxígeno y carece casi por completo de materia orgánica muerta; el agua es pobre en biodiversidad.

El contenido de nutrientes del agua caracterizará su nivel trófico. Las aguas eutróficas son ricas en nutrientes; mientras que las oligotróficas son pobres en ellos. En las aguas eutróficas crece gran cantidad de fitoplancton y existe, por lo tanto, una rica vida animal; en las oligotróficas es limitado el desarrollo del fitoplancton y, por consiguiente, el de todos los demás organismos. Los fosfatos desempeñan un papel muy importante, ya que es el factor limitante de las algas en las aguas continentales; en tanto que el sobreabonado puede conducir a la eutrofización de las aguas. 
Los niveles de saprobios y los niveles tróficos, aunque están relacionados, indican propiedades distintas de las aguas y no se corresponden necesariamente, como se muestra en el cuadro 3 .

Los aspectos planteados sintetizan algunos conceptos, definiciones e inter- pretaciones pertinentes para abordar los estudios multitemporales de la transformación ambiental y que atañen con hechos tanto simbólicos, como culturales, sociales y ecológicos, que trascienden ampliamente las connotaciones naturales y recaen en ámbitos de sistemas de alteridad territorio-cultura-sociedad-naturaleza.

\section{Cuadro 3. Niveles de saprobios y niveles tróficos}

\begin{tabular}{|c|c|}
\hline Clase/Nivel de saprobios & Nivel trófico \\
\hline $\begin{array}{l}\text { I: Oligosaprobio } \\
\text { Agua pura, rica en oxígeno. Relativamente po- } \\
\text { cas especies, reducido número de individuos. }\end{array}$ & $\begin{array}{l}\text { Oligotrófico } \\
\text { Agua clara, pobre en nutrientes; saturada } \\
\text { con más de un } 70 \% \text { de } \mathrm{O}_{2} \text {, incluso en zonas } \\
\text { profundas. }\end{array}$ \\
\hline $\begin{array}{l}\text { I/II: Oligosaprobio/ } \beta \text {-mesosaprobio } \\
\text { Consumo de oxígeno escaso. Gran variedad de } \\
\text { especies. }\end{array}$ & $\begin{array}{l}\text { Mesotrófico } \\
\text { Nutrientes y producción planctónica moderados. } \\
\text { En las zonas profundas } 100-30 \% \text { de } \mathrm{O}_{2} \text {. }\end{array}$ \\
\hline $\begin{array}{l}\text { II: } \beta \text {-mesosaprobio } \\
\text { Poco contaminada, rica en oxígeno. Muchas es- } \\
\text { pecies animales y vegetales. } \\
\text { II/III: } \beta \text {-mesosaprobio/ } \alpha \text {-mesosaprobio } \\
\text { "Críticamente" contaminada. La diversidad de } \\
\text { especies de las formas mayores retrocede. } \\
\text { III: } \alpha \text {-mesosaprobio } \\
\text { Con contaminación orgánica. Contenido en oxí- } \\
\text { geno bajo. Numerosos ciliados y bacterias. } \\
\text { III/IV: } \alpha \text {-mesosaprobio/polisaprobio } \\
\text { Consumo de oxígeno elevado. Posibilidades } \\
\text { de vida únicamente para organismos muy } \\
\text { especializados. }\end{array}$ & $\begin{array}{l}\text { Eutrófico } \\
\text { Agua rica en nutrientes. "Productiva": intenso } \\
\text { desarrollo de algas microscópicas y de } \\
\text { zooplancton. Profundidad de visión por lo gene- } \\
\text { ral inferior a } 2 \text { metros. Agua superficial a veces } \\
\text { sobresaturada de oxígeno, aguas profundas con } \\
\text { carencia periódica de oxígeno. }\end{array}$ \\
\hline $\begin{array}{l}\text { IV: Polisaprobio } \\
\text { El oxígeno falta por completo durante largos pe- } \\
\text { riodos. Desarrollo masivo de bacterias. }\end{array}$ & $\begin{array}{l}\text { Politrófico } \\
\text { Nutrientes siempre presentes y en gran cantidad. } \\
\text { Aguas en putrefacción de todo tipo. Aguas } \\
\text { profundas carentes periódicamente de oxígeno, } \\
\text { formación de ácido sulfhídrico. }\end{array}$ \\
\hline
\end{tabular}

Fuente: Streble \& Krauter, 1987. 


\section{Conclusiones}

Los principales aportes del ensayo involucran el estudio y conceptualización de lo ambiental desde una perspectiva amplia y holística, en la que se parte de una no neutralidad de los "hechos" espaciales. Estos son analizados, entendidos y explicados como cargados de historicidad y connotaciones ordenadoras, consecuencia de diversos procesos socioculturales y técnico-productivos desarrollados en las sociedades que han intervenido e interactuado en la dialéctica de conformación de espacialidades, entendidas como sistemas relacionales. Se plantean aproximaciones a visiones integrales de amplia espacio-temporalidad, lo cual implica lecturas polisémicas, tanto sociales como científicas, que permitan integrar múltiples aspectos biofísicos, sociales, históricos y culturales aportados por diversas disciplinas, con características, enfoques y niveles jerárquicos diferentes. Esta multiplicidad de visiones se concreta en la categoría geográfica de paisaje, en la cual se expresan las herencias de las relaciones sucesivas entre hombre, sociedad, cultura y naturaleza.

\section{Bibliografía}

Ángel Maya, Augusto (1995): La fragilidad ambiental de la cultura. Bogotá: Editorial Universidad Nacional: Instituto de Estudios Ambientales, IDEA. 127 p.

Bayliss-Smith, Tim \& Susan Owens (1994): “The Environmental Challenge”. En: Gregory, Derek; Martin, Ron \& Smith, Graham (eds.): Human Geography: Society, Space, and Social Science. Minneapolis: MacMillan, pp. 113-145.

Bonilla Godoy, Jaime (2001): "Reflexiones acerca de los fundamentos teórico-metodológicos en Geografía Histórica. Visiones contemporáneas”. Cuadernos de Geografía: Revista del Departamento de Geografía de la Universidad Nacional de Colombia. 10(1): 123-147.

Bovet Pla, María del Tura \& Ribas Vilàs, Jordi (1992): "Metodología general de los estudios de paisaje”. En: Bolós, María de (ed.): Manual de Ciencia del Paisaje. Barcelona: Masson, pp. 123-134.

Cabarcas Antequera, Hernando (1994): Bestiario del Nuevo Reino de Granada: La imaginación animalística medieval y la descripción literaria de la naturaleza americana. Bogotá: Imprenta Patriótica del Instituto Caro y Cuervo, 196 p. (Colección Daniel Samper Ortega; Núm. 1).

CAPRA, Fritjof (1998): La trama de la vida: Una nueva perspectiva de los sistemas vivos. Barcelona: Anagrama, pp. 171-205; 275-304.

192 Ramón Alberto Serna Isaza 
Castellanos, Juan de (1955): Elegías de varones ilustres de Indias. Bogotá: Biblioteca de la Presidencia de la República, 4 v.

CASTRILlón, Alberto (1997): "Fitogeografía, paisaje y territorialidad al comienzo del siglo xIX”. Boletín Cultural y Bibliográfico, 34(46): 61-81.

Ceballos Gómez, Diana Luz (1995): Hechicería, brujería e inquisición en el Nuevo Reino de Granada: un duelo de imaginarios. Medellín: Universidad Nacional de Colombia, $249 \mathrm{p}$.

CRONON, William (2002):. "Un lugar para relatos: naturaleza, historia y narrativa”. En: Palacio, Germán \& Ulloa, Astrid (eds.): Repensando la naturaleza: Encuentros y desencuentros disciplinarios en torno a lo ambiental. Bogotá: Universidad Nacional de Colombia, pp. 29-65.

Díaz Muñoz, María de los Ángeles (1992): "Espacio y tiempo en la actividad cotidiana de la población". En: Bosque Sendra, Joaquín; De Castro Aguirre, Constancio; Díaz Muñoz, María Ángeles y Escobar Martínez, Francisco Javier (eds.): Prácticas de Geografía de la percepción y de la actividad cotidiana. Barcelona: Oikos-Tau, pp. 15-44.

Díaz-Piedrahita, Santiago (1991): La botánica en Colombia, hechos notables en su desarrollo. Bogotá: Academia Colombiana de Ciencias Exactas, Físicas y Naturales, 125 p. (Colección Enrique Pérez-Arbeláez; núm. 6).

Escobar, Arturo (1999): El final del salvaje: Naturaleza, cultura y política en la antropología contemporánea. Bogotá: Instituto Colombiano de Antropología, 418 p. (Colección Antropología en la Modernidad; núm. 3).

Estruch García, Xavier (1992): "Las evaluaciones de impacto ambiental en los estudios de paisaje”. En: Bolós, María de (ed.): Manual de Ciencia del Paisaje. Barcelona: Masson, pp. 126-189.

ETter, Andrés (1994): “Consideraciones generales para el análisis de la cobertura vegetal”. En: Taller Sobre Cobertura Vegetal ( $1^{\circ}: 1994$ : Bogotá). Memorias del Primer Taller sobre Cobertura Vegetal. Bogotá: Instituto Geográfico Agustín Codazzi, pp. 11-23.

FALS BoRDA, Orlando \& Mora-Osejo, Luis Eduardo (2001): Manifiesto por la autoestima en la ciencia colombiana. Bogotá: Academia Colombiana de Ciencias Exactas, Físicas y Naturales, $6 \mathrm{p}$.

Fernández de Piedrahita, Lucas (1942): Historia general del Nuevo Reino de Granada. Bogotá: Biblioteca Popular de Cultura Colombiana, 4V.

Fernández de Oviedo, Gonzalo (1995): Sumario de la Natural Historia de las Indias. Bogotá: Instituto Caro y Cuervo (Colección Fabio Lozano y Lozano). 
García, Rolando (1994): "Interdisciplinariedad y sistemas complejos". En: Leff, Enrique et al.: Ciencias Sociales y Formación Ambiental. Barcelona: Gedisa, pp. 85-124.

GLACKEN, Clearence J. (1967): Traces on the Rhodian shore: nature and culture in Western thought from ancient times to the end of the eighteenth century. Berkeley: University of California.

Gómez BERNAL, Hildebrando (2002): "Breve reseña histórica del maíz". En: Boletín de la Academia de Historia de Cundinamarca, 9(22): 73-75 (jun.).

HERRERA ÁNGel, Marta (2002): Ordenar para controlar. Ordenamiento espacial y control político en las llanuras del Caribe y en los Andes Centrales Neogranadinos. Siglo XVIII. Bogotá: Instituto Colombiano de Antropología e Historia, 344 p.

Leal, Claudia (2002): "La naturaleza en los estudios sociales". En: Palacio, Germán \& Ulloa, Astrid (eds.): Repensando la naturaleza: Encuentros y desencuentros disciplinarios en torno a lo ambiental. Bogotá: Universidad Nacional de Colombia, pp. 123-137.

LefF, Enrique (1994): "Sociología y ambiente: Formación socioeconómica, racionalidad ambiental y transformaciones del conocimiento". En: Leff, Enrique (comp.): Ciencias Sociales y Formación Ambiental. Barcelona: Gedisa, pp. 17-84.

LewIS, Arthur W. (1955): Economic Growth Theory. London: Allen \& Unwin, 435 p.

Londoño, Eduardo (1994): "Los muiscas en las crónicas y los archivos". En: Revista Colombiana de Antropología, 31: 107-120.

Llano Restrepo, María Clara \& Marcela Campuzano Cifuentes (1994): La chicha, una bebida fermentada a través de la historia. Bogotá: Instituto Colombiano de Antropología, 160 p.

MÁRQUEZ, Germán (2001): "De la abundancia a la escasez: La transformación de ecosistemas en Colombia". En: Palacio, Germán: La naturaleza en disputa: Ensayos de Historia Ambiental de Colombia 1850-1995. Bogotá: Universidad Nacional de Colombia, pp. 323-480.

Martínez de Pisón, Eduardo (1998): "El concepto de paisaje como instrumento de conocimiento ambiental. En: Martínez de Pisón, Eduardo (ed.): Paisaje y medio ambiente. Valladolid: Universidad de Valladolid, pp. 9-28.

Molano Barrero, Joaquín (1995): “Arqueología del paisaje”. Cuadernos de Geografía: Revista del Departamento de Geografía de la Universidad Nacional de Colombia, 5(2): 1-10.

MoRIN, Édgar (2001): Introducción al pensamiento complejo. Barcelona: Gedisa, 167 p.

MuÑoz JiMÉNEZ, Julio (1998): "Paisaje y Geosistema. Una aproximación desde la Geografía Física”. En: Martínez de Pisón, Eduardo (ed.): Paisaje y medio ambiente. Valladolid: Universidad de Valladolid, pp. 45-55.

194 Ramón Alberto Serna Isaza 
Nieto Olarte, Mauricio (2000): Remedios para el Imperio: Historia natural y la apropiación del Nuevo Mundo. Bogotá: Instituto Colombiano de Antropología, 279 p.

OBREGÓN, Diana (1988-1989): "El sentimiento de nación en la literatura médica y naturalista de finales del siglo XIX en Colombia”. Anuario Colombiano de Historia Social y de la Cultura, 16/17; 141-161.

Ortega Cantero, Nicolás (1998): Paisaje y Cultura. En: Martínez de Pisón, Eduardo (ed.): Paisaje y medio ambiente. Valladolid: Universidad de Valladolid, pp. 137-150.

Oviedo, Basilio Vicente de (1930): Cualidades y riquezas del Nuevo Reino de Granada: Manuscrito del siglo XviII. Bogotá: Imprenta Nacional, 337 p.

Patiño, Víctor Manuel (1964): Plantas cultivadas y animales domésticos en América Equinoccial. Tomo II: Plantas alimenticias cultivadas en la región ecuatorial del Nuevo continente. Cali: Imprenta Departamental, 365 p.

(1967): Plantas cultivadas y animales domésticos en América Equinoccial. Tomo III: Fibras, Medicinas, Misceláneas. Cali: Imprenta Departamental, 572 p.

(1977): Aspectos históricos sobre los recursos naturales y las plantas útiles en Colombia. Bogotá: Instituto Colombiano de Cultura, 612 p. (Biblioteca Básica Colombiana, Tercera Serie, núm. 27).

Peña RoA, Paola Andrea (2001): "Expediciones naturales y científicas en Colombia". Agenda Cultural: Boletín de la Universidad Jorge Tadeo Lozano, 121: 16-23 (mar.), Bogotá.

PINILla, Gabriel A. (1998): Indicadores biológicos en ecosistemas acuáticos continentales de Colombia: Compilación bibliográfica. Bogotá: Fundación Universidad de Bogotá Jorge Tadeo Lozano, 67 p.

SAmper Ortega, Daniel (1937): La obsesión. Bogotá: Minerva, 254 p. (Selección Samper Ortega de Literatura Colombiana; núm. 18).

Santos, Milton (2000): La naturaleza del espacio. Técnica y tiempo. Razón y emoción. Barcelona: Ariel, 348 p.

Serna Isaza, Ramón Alberto (2001): "Desarrollo sostenible y ciudad”. Perspectiva Geográfica: Revista del Programa de Estudios de Posgrado en Geografía, 6: 137-175.

Simmons, I. G. (1990): Changing the face of the earth: culture, environment, history. Oxford: Basil Blackwell, 487 p.

Simón, Fray Pedro (1981-1982): Noticias historiales de las conquistas de Tierra Firme en las Indias Occidentales. Bogotá: Banco Popular, 7 v.

Streble, Heinz y Krauter, Dieter (1987): Atlas de los Microorganismos de Agua Dulce: La vida en una gota de agua. Barcelona: Omega, $340 \mathrm{p}$.

Perspectiva Geográfica Núm. 11, 2005 195 
Suárez Moreno, Mario Francisco (2000): "Cibergeografía”. Perspectiva Geográfica: Revista del Programa de Estudios de Posgrado en Geografía, 5: 115-130.

Tovar, Ramón A. (1996): El Enfoque Geohistórico. Valencia, Venezuela: Universidad de Carabobo, $185 \mathrm{p}$.

UlloA, Astrid (2002): "De una naturaleza dual a la proliferación de sentido: La discusión antropológica en torno a la naturaleza, la ecología y el medio ambiente". En: Palacio, Germán \& Ulloa, Astrid (eds.): Repensando la naturaleza: Encuentros $y$ desencuentros disciplinarios en torno a lo ambiental. Bogotá: Universidad Nacional de Colombia, pp. 139-154.

Unwin, Tim (1995): El lugar de la geografía. Madrid: Cátedra, 342 p.

VezGA, Florentino (1971): La Expedición Botánica. Cali: Carvajal, 263 p.

Zambrano Pantoja, Fabio (2000): “Bogotá y su región: Una mirada de larga duración”. En: Corporación Autónoma Regional de Cundinamarca. S.O.S. Sabana de Bogotá. Bogotá: CAR, pp. 17-44.

Fecha de recepción: abril de 2004 Fecha de aprobación: junio de 2004

196 Ramón Alberto Serna Isaza 


\title{
Crecimiento, morfología y estructura urbanos en el proceso de urbanización de Zipaquirá
}

Urban growth, morphology and structure in the Zipaquirá's urbanization process

\author{
Guillermo Hernando Quintana Machado*
}

\section{Resumen}

Presenta unos acápites del trabajo de investigación denominado Análisis geográfico del proceso reciente de urbanización en el municipio de Zipaquirá. En el análisis del proceso de urbanización inciden múltiples variables. El presente escrito se centra en el crecimiento urbano desde 1970 a la fecha y en la morfología y estructura urbanas de Zipaquirá como factores incidentes que fueron y son determinantes de la actual mancha urbana del municipio. Estas variables se operacionalizarán relacionándose con las diferentes dinámicas territoriales, en torno a la estratificación socioeconómica, valor y uso del suelo.

Palabras clave: Proceso de urbanización, Crecimiento urbano, Estructura urbana, Morfología urbana, Zipaquirá.

* Ingeniero Catastral y Geodesta. Esp. en Sistemas de Información Geográfica. M.Sc. en Geografía.

Perspectiva Geográfica Núm. 1 1, 2005 197 


\section{Abstract}

These are fragments of the investigation called "Geographic analysis of the Zipaquirá's municipally urbanization recent process", in which multiple variables have incidence. The present text focus the urban growth since 1970 to the date, and the Zipaquirá morphology and urban structure, as factors which were and are determinants in the actual urban city development. These variables are operationally related with the different territorial dynamics, around the social economical situation, and around the land value and way of use.

Key words: Urbanization process, Urban growth, Urban structure, Urban morphology, Zipaquirá.

198 Guillermo Hernando Quintana Machado 